Fernandez, D. \& Griffiths, M.D. (2019). Psychometric instruments for problematic pornography use: A systematic review. Evaluation and the Health Professions, Epub ahead of print

\begin{abstract}
Despite a lack of consensus in the field about how best to conceptualize problematic pornography use, psychometric instruments have nonetheless been developed to assess the construct. The present systematic review aimed to: (i) identify psychometric tools that have been developed to assess problematic pornography use; (ii) summarize key characteristics, psychometric properties and strengths and limitations of instruments for problematic pornography use; (iii) compare the instruments' theoretical conceptualizations of problematic pornography use; and (iv) evaluate each instrument on their ability to assess various core components of addiction. Twenty-two instruments assessing problematic pornography use were reviewed. Results indicated that while the instruments had different conceptualizations of problematic pornography use, addiction still emerged as the most common theoretical framework used by the instruments. Five of the most commonly assessed addiction components across the different instruments were (1) impaired control; (2) salience; (3) mood modification; (4) interpersonal conflict, and (5) general life conflict. Contextual factors that may potentially affect the assessment of problematic pornography use and recommendations for researchers and clinicians are discussed.
\end{abstract}

Keywords: Pornography; Pornography addiction; Sex addiction; Problematic pornography use; Pornography psychometrics 


\section{Psychometric instruments for problematic pornography use: A systematic review}

Pornography use has become increasingly prevalent worldwide (Hald, Kuyper, Adam \& de Wit, 2013; Hald \& Mulya, 2013; Wright, 2013), which can be explained in part to the advent of the internet and increased internet access (Buzzell, 2005). Two decades ago, Cooper (1998) had predicted the impact that the internet would have on sexuality moving into the $21^{\text {st }}$ century, proposing the Triple A Engine of access, affordability and anonymity factors the internet possess that make accessing pornography online particularly convenient. Recently, PornHub (the largest pornography site on the internet) reported in their annual review that they received 28.5 billion visits in 2017 , with a daily average of 81 million visits a day (Pornhub.com, 2018).

Pornography use has therefore been the subject of much scientific attention, with researchers especially interested in investigating the psychological effects of viewing pornography. Research on self-perceived effects of pornography consumption has shown that pornography users report positive effects such as increasing their sexual knowledge and improving their sex life, but also negative effects such as having unrealistic sexual expectations, relationship problems, and addiction (Hald \& Malamuth, 2008; Mamun, Arafat, Ambiatunnahar \& Griffiths, 2018; McKee, 2007). However, at present there is still ongoing disagreement within the scientific community about the negative effects of pornography, primarily about the possibility of being genuinely addicted to pornography. Proponents of the pornography addiction model have argued that pornography is addictive due to it being a particularly novel and 'supranormal' stimulus (Hilton Jr., 2013), and that symptoms of excessive pornography use fit neatly within an addiction framework, sharing similar neurobiological mechanisms with substance addictions and other behavioral addictions (Gola et al., 2017; Love, Laier, Brand, Hatch \& Rajela, 2015). Opponents of the model on the other hand have challenged the credibility and very existence of the notion in the first place (Voros, 2009), and have suggested that supposed 'addictive' use of pornography can be explained by non-pathological factors including high libido, tendency towards sensation-seeking, and religious values that conflict with personal sexual desires (Ley, Prause \& Finn, 2014).

The controversy surrounding pornography addiction is part of a larger debate about whether sexual addiction more generally should be officially recognized as a clinical disorder. To date, sexual addiction has never received formal recognition as a disorder, despite clinical evidence documenting many individuals seeking treatment for problematic 
excessive sexual behaviors (Kraus, Martino \& Potenza, 2016; Reid et al., 2012). Various theoretical models conceptualizing problematic excessive sexual behavior in different ways have arisen over the years, including sexual addiction (Carnes, 1983; Goodman, 1992), sexual impulsivity (Barth \& Kinder, 1987), compulsive sexual behavior (Coleman, 1991), and more recently Hypersexual Disorder (HD; Kafka, 2010). However, in 2013 the American Psychiatric Association rejected the proposal for the inclusion of HD into the DSM-5 (Reid \& Kafka, 2014), under which pornography dependence would have been subsumed as a specifier. Inadequate empirical evidence and lack of expert consensus on the conceptualization of the disorder was cited as the main reason for its rejection (Hartmann, 2013). However, more recently, the World Health Organization (WHO) included the diagnosis of compulsive sexual behavior disorder (CSBD) as an impulse-control disorder in the ICD-11 (Kraus et al., 2018; Reed et al., 2019; World Health Organization [WHO], 2019), under which compulsive use of pornography would be subsumed. This would be the first time that compulsive pornography has been used a formal diagnosis within clinical settings. It is important to note that CSBD is not being ruled out as a behavioral addiction, but that for ICD-11, a conservative approach has been taken in categorizing it as an impulse-control disorder because there is insufficient evidence to determine whether the disorder is similar to other recognized forms of addiction including substance use disorders, gambling, and gaming (Kraus et al., 2016; Kraus et al., 2018).

Nonetheless, whether or not pornography addiction should be recognized as a disorder, scientific investigation of the phenomenon is still ongoing. Psychometric instruments have been developed over the years to assess various aspects of problematic pornography use. In the absence of official diagnostic criteria conceptualizing compulsive and/or addictive use of pornography, the construct has been explored from multiple angles, using different conceptualizations and theoretical frameworks. As a result, the term 'problematic' has often been used in lieu of the term 'addiction' or 'compulsion' in the literature. The term 'problematic pornography use' is therefore used in the present review because it covers any theoretical conceptualization of the concept. The variety of approaches to conceptualization has led to conclusions being drawn about problematic pornography use without a clear consensus in the field about agreed upon operational definitions and assessment of the construct, which will ultimately influence the understanding, assessment, and treatment of the problem. Hence, there is a need for systematic evaluation of psychometric instruments that have been developed to assess various aspects of problematic pornography use. 


\section{Previous reviews of psychometric instruments assessing problematic sexual behavior}

Sexual addiction/hypersexual disorder. There have been relatively recent reviews pertaining to psychometric instruments for sexual addiction/hypersexual disorder in general. For example, Hook, Hook, Davis, Worthington Jr. and Penberthy (2010) evaluated psychometric properties of psychometric tools for sexual addiction, while Womack, Hook, Ramos, Davis and Penberthy (2010) evaluated the ability of psychometric tools for HD in assessing diagnostic criteria of HD. More recently, Montgomery-Graham (2016) conducted an updated psychometric evaluation of the most researched HD instruments. However, these reviews did not include instruments that had been developed to specifically assess problematic pornography use.

Problematic pornography use. There have also been recent reviews more specifically focused on conceptualization and assessment of problematic pornography use. For example, Eleuteri, Tripodi, Petruccelli, Rossi and Simonelli (2014) reviewed the strengths and weaknesses of psychometric tools for online sexual activities from 2004-2014, including instruments for problematic pornography use. Wéry and Billieux (2016) reviewed the conceptualization, assessment, and treatment of problematic cybersex, and provided a brief overview of instruments for the assessment of problematic cybersex, most of which could be applied to problematic pornography use. Duffy, Dawson and Das Nair (2016) reviewed the different definitions of 'self-perceived pornography addiction' in the literature and its reported impact. A recent review of the state of evidence for online pornography addiction (Alarcón, de la Iglesia, Casado \& Montejo, 2019) briefly touched on the most widely used assessment tools for problematic pornography use.

However, to date, there has been no review evaluating psychometric instruments for problematic pornography use in terms of their diagnostic features. A major aim of the present review is therefore to compare different psychometric instruments for problematic pornography use on their ability to assess common components of addiction. The addiction model is used as a framework for this evaluation because addiction symptoms share significant commonalities with symptoms of related theoretical models, for instance, accounting for impulsivity in impulse control disorder models and compulsivity in compulsive behavior models (Cuzen \& Stein, 2014; Kingston \& Firestone, 2008). Although having etiological dissimilarities with addiction, the symptoms proposed in diagnostic criteria for HD and CSBD can be interpreted using an addiction framework. Some conceptualizations of addiction may also include tolerance and withdrawal (Griffiths, 2005), symptoms which are unique to addiction but not present in impulsivity or compulsivity models. Comparing 
psychometric instruments on their capacity to assess common components of addiction has been conducted for other problematic behaviors such as pathological gaming (King, Haagsma, Delfabbro, Gradisar \& Griffiths, 2013) but has yet to be applied to problematic pornography use. The aims of this systematic review are therefore to: (i) identify psychometric tools that have been developed to assess problematic pornography use; (ii) summarize key characteristics, psychometric properties, and strengths and limitations of instruments for problematic pornography use; (iii) compare the instruments' theoretical conceptualizations of problematic pornography use; (iv) evaluate each instrument on their ability to assess various core components of addiction.

\section{Method}

Papers were identified via electronic database searches of Scopus, Web of Science, PubMed, PsycArticles, PsycInfo and PsycTests. In order to identify literature related to psychometric tools assessing problematic pornography use, the following search terms were used: (problem* OR addict* OR compulsiv* OR dependen*) AND pornography AND (assessment OR scale OR instrument OR measurement). The search terms yielded 5,873 results in total.

Studies were first screened for relevance by reviewing titles and abstracts. Full-text papers were then assessed for eligibility based on the following inclusion criteria: (i) published in English; (ii) published in a peer-reviewed journal; (iii) describes the development, adaptation, or initial use of an original self-report psychometric tool that assesses at least one aspect of problematic pornography use on at least one subscale of the instrument. Papers were excluded if (i) the psychometric tool described was not a self-report instrument, and (ii) if the purpose of the psychometric tool described was not to specifically assess aspects of pornography use even if the instrument could be used for such a purpose. For example, there are scales that have been developed to assess HD that could be directly applicable to problematic pornography use - the Hypersexual Behavior Inventory (HBI, Reid, Garos \& Carpenter, 2011), the Hypersexual Behavior Consequences Scale (HBCS; Reid, Garos \& Fong, 2012), and the Hypersexual Disorder Screening Inventory (HDSI; Parsons et al., 2013) were excluded on the basis that they assess HD more broadly (despite the authors explicitly stating that the instruments could be used to assess problematic pornography use). While problematic pornography use has been argued to be a subset of HD (Kafka, 2010), a review of HD instruments falls outside the scope of the present study. However, psychometric tools assessing 'cybersex' or 'internet sex' were included if some items on the instrument could be directly applied to online pornography use. Although such 
instruments were not designed to target pornography use specifically, many of these tests refer to 'cybersex' or 'online sexual activities' that could be reasonably argued to be a proxy for online pornography use. Reference lists of included studies were also searched to identify further relevant papers. Figure 1 depicts the Preferred Reporting Items for Systematic Reviews and Meta-Analyses (PRISMA) flow diagram summarizing the systematic search process.

\section{FIGURE 1 ABOUT HERE}

\section{Instrument evaluation}

Instrument characteristics and psychometric properties. For each instrument, information pertaining to general instrument characteristics (i.e., item content, item sensitivity, factor structure, and original validation sample), theoretical conceptualizations of problematic pornography use, and psychometric properties (i.e., reliability and validity) was extracted. Reliability was evaluated in terms of internal consistency and test-retest reliability of the instruments and their subscales. Rules of thumb for evaluating internal consistency provided by Cicchetti (1994) were used, whereby below .70 is below an acceptable threshold, between .70 and .79 is 'fair', between .80 and .89 is 'good', and .90 and above is 'excellent'. Validity was evaluated in terms of convergent and discriminant validity, criterion-related validity (i.e., concurrent or predictive validity), and whether the factor structure of the test was derived from factor analytic techniques. Criterion-related validity was operationally defined in the present review as the scores on the instrument having a correlation with behavioral indicators of pornography use (i.e., pornography consumption in terms of frequency or duration), or to an established existing measure of problematic pornography use in the field.

Components of addiction. Based on similar methodology used in King et al. (2013), the psychometric instruments were compared on their ability to assess different components of addiction. A total of 17 components of addiction were included in the comparison. Griffiths' (2005) six core components of addiction - salience, mood modification, withdrawal, tolerance, relapse, and conflict - were also included. Salience refers to an activity becoming the most important thing in the person's life, dominating their thinking and behavior. Mood modification refers to the use of the behavior to produce shifts in a person's mood state or to 'self-medicate' negative feelings. Withdrawal refers to the unpleasant emotional states that are experienced when the behavior is suddenly stopped. Tolerance refers to the person needing to increase frequency and/or amount of time spent on the 
behavior in order to achieve previous similar effects. With problematic sexual behaviors, this may also involve increased risk-taking or increased variety of stimuli or behaviors to achieve the same effect. Relapse refers to the person reverting to earlier patterns of behavior after periods of abstinence or control. Conflict refers to harmful consequences arising from the addictive behavior. The conflict component in the present review was further broken down across nine domains. First, interpersonal conflict refers to problems arising in interpersonal relationships, including a disruption of the person's social functioning (e.g., isolating, getting into arguments with significant others, etc.). Second, intrapsychic conflict refers to a subjective struggle experienced within the individual as a result of the behavior, which includes any psychological distress experienced. Third, educational/occupational conflict refers to problems in academic and/or job functioning. Fourth, financial conflict refers to financial problems experienced as a result of the addition - for example, accumulating debt in order to continue engaging in the behavior. Fifth, sleep conflict refers to the person losing sleep to engage in the behavior. Sixth, general life conflict refers to any negative consequences experienced that affects the person's life more generally. Seventh, household/hobby conflict refers to the behavior interfering with household duties or leisure activities. Eighth, negative attitude conflict refers to any negative attitudes that are experienced as a result of engagement in the behavior. Finally, ninth, sex life conflict refers to the engagement in the activity having a detrimental effect on the person's sex life. Other core components of addiction not explicitly covered by Griffiths' model were also included and comprised impaired control, craving, use despite harm, and deception (American Psychiatric Association [APA], 2013; Maddux \& Desmond, 2000; Shaffer, 1999). Impaired control refers to the person having diminished control over the behavior as evidenced by engaging in the behavior even when they do not want to, or engaging in the behavior more frequently or for a longer duration than intended. Craving refers to the subjective experience of intense desire to engage in the behavior. Use despite harm refers to continued engagement in the behavior despite experiencing negative consequences. Deception refers to hiding, being secretive, or lying about the behavior. This was included because it is listed as a diagnostic criterion for gambling disorder in the DSM-5 (APA, 2013), and therefore could be an indicator of addiction for other problematic behaviors as well.

Individual items on each instrument were reviewed to determine which components of addiction, if any, they assessed. Where items appeared to be assessing more than one addiction component simultaneously, it was coded as such. Both authors of the present review coded the items independently and reached a consensus on any discrepancies in 
coding. For purpose of comparison, the proposed diagnostic criteria for HD and CSBD were also included in the evaluation. HD criteria and CSBD criteria correspond to ten and nine addiction components respectively. All nine addiction components captured by CSBD criteria (salience, impaired control, relapse, craving, interpersonal conflict, intrapsychic conflict, educational/occupational conflict, general life conflict, and use despite harm) were also assessed by HD criteria - the only difference being that HD criteria assess mood modification, while CSBD criteria do not.

\section{Results}

A total of 20 papers describing 22 psychometric instruments were found and included in the present review. Table 1 summarizes characteristics of each psychometric tool.

\section{TABLE 1 ABOUT HERE}

\section{Theoretical models and conceptualizations of problematic pornography use}

Although all the instruments assess some aspect of problematic pornography use, there are notable variations in their conceptualizations of problematic pornography use and intended purpose of use. These are outlined below.

Addiction. Out of the 22 instruments, 13 used an addiction framework in conceptualizing problematic pornography use. Of these, four were based on two existing measures of internet addiction that were adapted to online sexual behavior including pornography use (i.e., Compulsive Internet Use Scale-adapted to Sexually Explicit Media [CIUS-Adapted] and Compulsive Use of Sexually Explicit Internet Material were based on the Compulsive Internet Use Scale [CIUS; Meerkerk, van den Eijnden, Vermulslt \& Garretsen, 2009], and the Internet Addiction Test-Sex [IAT-Sex] and Short-Internet Addiction Test-Sex [s-IAT-Sex] were based on the Internet Addiction Test [IAT; Young, 1998]), and one instrument (i.e., Internet Sex Screening Test [ISST]) assesses internet sex addiction more generally but includes items concerning online sexual behavior that could be applied to problematic pornography use. The most common theoretical model of addiction used was Griffiths' (2005) components model of addiction, with three scales (CIUS-Adapted, Compulsive Use of Sexually Explicit Internet Material, and the Problematic Pornography Consumption Scale [PPCS]) incorporating it as part of their theoretical framework.

Compulsive behavior. Two instruments (i.e., Compulsive Pornography Consumption [CPC] Scale and Cyberporn Compulsivity Scale [CCS]) conceptualized problematic pornography use within models of compulsive behavior. The CPC is based on DSM-5 
definitions of obsessive-compulsive disorders, while the CCS is based on Kalichman and Rompa's (1995) Sexual Compulsivity Scale which was itself based on conceptualizations of problematic sexual behavior as compulsions.

Hypersexual behavior. One instrument, the Pornography Consumption Inventory (PCI), was designed to assess motivations for pornography use among hypersexual men. The instrument was designed taking into consideration empirical and clinical findings on the proposed HD diagnosis (Kafka, 2010). Thus, problematic pornography use is conceptualized as a hypersexual behavior.

Deficient self-regulation. Three instruments (i.e., Habit Strength Scale, Deficient SelfRegulation Scale, and Negative Consequences Scale) - forming part of a hypothesized model investigating different elements of unregulated media usage - were conceptualized based on a social-cognitive theory of dysregulated media use, and clearly differentiate their model from addiction models. These instruments were intended to assess problematic pornography use that exists on a spectrum of dysregulated media usage, from mild dysregulation with the absence of serious negative life consequences, to severe dysregulation that may fall within the realms of addiction. Thus, the authors suggest that these instruments assess issues with self-regulation rather than addiction.

Negative effects. Three instruments - the Pornography Consumption Effects Scale (PCES), PCES Short-Form (PCES-SF), and PCES-Revised (PCES-R) examine the effects of pornography consumption (both positive and negative), with negative effects being directly applicable to problematic pornography use. These scales are atheoretical and approach pornography consumption from a neutral perspective based on sexuality and pornography research.

\section{Components of addiction}

The psychometric instruments were compared on their ability to assess different components of addiction (see Table 2). In terms of breadth of coverage, the instruments that were designed as comprehensive measures of addiction are able to assess more components of addiction. Among these tests, the scales that had the widest coverage of addiction components were the Cyber Pornography Use Inventory (CPUI; n=11), the s-IAT-Sex $(n=10)$, the IAT-Sex $(n=10)$. On the other hand, some scales only assess specific components of addiction (e.g., Pornography Consumption Questionnaire [PCQ] for craving or the PCES, the PCES-R and the PCES-SF for various negative consequences) providing more depth examining a specific component. 
The most frequently assessed components of addiction across the instruments were, in descending order: impaired control $(n=15)$, salience $(n=14)$, mood modification $(n=13)$, interpersonal conflict $(\mathrm{n}=11)$ and general life conflict $(\mathrm{n}=11)$. Both interpersonal conflict and general life conflict emerged as the most frequently assessed types of conflict, with intrapsychic conflict $(n=7)$, educational/occupational conflict $(n=6)$, sex life conflict $(n=6)$ assessed slightly less frequently. In contrast, conflict with sleep $(n=4)$, negative attitudes $(n=3)$, finance $(n=2)$ household and hobbies $(n=2)$ were the most infrequently assessed. Withdrawal $(n=9)$ was much more frequently assessed than tolerance $(n=3)$. Of the three scales that assessed tolerance, two of the scales (ISST and CPUI) used the same item "I have increased the risks I take online (give out name and phone number, meet people offline, etc.)" that do not refer to pornography use but rather social behavior online with a sexual purpose, and only loosely assesses tolerance. The PPCS was the only instrument that explicitly assessed tolerance. Relapse $(\mathrm{n}=7)$ was infrequently explicitly assessed compared to impaired control $(\mathrm{n}=15)$, although whenever relapse was assessed, impaired control was arguably also implicitly assessed. Craving $(n=5)$, deception $(n=5)$, and use despite harm $(n=2)$ were assessed much less frequently.

\section{TABLE 2 ABOUT HERE}

\section{Psychometric properties}

Reliability. Cronbach's alpha coefficients for all the instruments met a minimum threshold of .70, except for two subscales of the ISST (online sexual spending [.61] and interest in online sexual behavior [.51]). Test-retest reliability coefficients were reported for only three instruments (PCI, PCQ and Passion Scale).

Validity. As part of their development, most instruments demonstrated evidence for convergent and/or discriminant validity except the CCS, CPUI, ISST and PPCS. Fourteen out of 22 instruments demonstrated evidence of criterion-related validity except the CCS, CPUI, Compulsive Use of Sexually Explicit Internet Material, Deficient Self-Regulation scale, Negative Consequences scale, PCES-R, PCES-SF. Sixteen out of the 21 instruments used factor analysis to evaluate test dimensionality. The structure of the CCS, Compulsive Use of Sexually Explicit Internet Material Scale, the IAT-Sex, ISST, and Passion Scale-Pornography were not supported by factor analysis.

\section{Summary of instruments for problematic pornography use}


Each of the 22 instruments included in the present review are summarized in detail below, along with a summary of their most salient characteristics and respective strengths and limitations.

\section{Adaptations of the Compulsive Internet Use Scale (CIUS)}

Two instruments are adaptations of the Compulsive Internet Use Scale (CIUS; Meerkerk et al., 2009), a scale that was originally designed to assess the severity of compulsive internet use. The CIUS is based on Griffiths' (1999) six criteria for addiction, along with DSM-IV criteria for substance dependence and pathological gambling, and uses an addiction theoretical framework.

Compulsive Internet Use Scale adapted to Sexually Explicit Media. The Compulsive Internet Use Scale adapted to Sexually Explicit Media (CIUS-Adapted; Downing Jr., Antebi \& Schrimshaw, 2014) is a 13-item scale that assesses "compulsive use of internet sexually explicit material" (Downing Jr. et al., p.1127). The scale has a single factor, with sample items such as "How often do you find it difficult to stop accessing these websites when you are online?", "How often do you neglect your daily obligations (work, school or family life) because you prefer to access these websites?" and "How often do you access these websites when you are feeling down?", rated on a 5-point scale, from 'never' to 'very often'. The scale assesses nine addiction components including salience, impaired control, withdrawal, relapse, mood modification, interpersonal conflict, intrapsychic conflict, educational/occupational conflict and sleep conflict. No cut-off score was provided to differentiate problematic from non-problematic pornography users

Sample. The CIUS-adapted was validated on a sample of men who have sex with men.

Reliability. The CIUS-Adapted has excellent internal consistency $(\alpha=.92)$, but temporal stability of the instrument was not reported.

Validity. The scale's single-factor structure was derived from principal components analysis. The scale demonstrated evidence of convergent validity, being positively correlated with sexual sensation seeking (Kalichman \& Rompa, 1995), frequency of sexual fantasies similar to sexual fantasies viewed online, boredom, and sexual frustration. The scale has evidence for criterion-related validity, being correlated with time spent viewing online sexually explicit media.

Strengths and limitations. Overall, the CIUS-adapted has robust psychometric properties and a broad coverage of addiction components $(n=9)$. However, the scale was validated in a sample of men who have sex with men, and thus its generalizability beyond 
this subset of pornography users is unknown. Additionally, the way the items have been rephrased and adapted from the CIUS to focus mainly on accessing and using 'these websites' to watch pornography may not account for other ways pornography users may access online pornography without needing to spend time on specific websites (e.g., downloading pornography from peer-to-peer networks).

\section{Compulsive Use of Sexually Explicit Internet Material Scale}

The Compulsive Use of Sexually Explicit Internet Material Scale (Doornwaard, van den Eijnden, Baams, Vanwesenbeeck \& Bogt, 2016) is a six-item scale that assesses "symptoms of compulsive searching for/viewing of pornography on the internet" (p.76). The scale has a single factor and sample items include: "How often do you find it difficult to stop searching for/viewing porn on the internet?" and "How often do you look forward to the next time you can search for/view porn on the internet?" The scale assesses six components of addiction (i.e., salience, impaired control, withdrawal, mood modification, interpersonal conflict and sleep conflict). No cut-off score was provided to differentiate problematic from non-problematic pornography users.

Sample. The scale was adapted for use with a sample of male adolescents.

Reliability. The scale has good internal consistency $(\alpha=.83-.85)$, but temporal stability of the scale was not reported.

Validity. Factor analysis was not used to validate the factor structure of the scale. Positive correlations between the scale and depression (Kandel \& Davies, 1982), excessive sexual interest (Snell \& Papini, 1989), affective psychopathy as assessed by the callousunemotional dimension of the Youth Psychopathic Traits Inventory-Short Version (van Baardewijk et al., 2010), and negative correlations between the scale and global self-esteem, as assessed by an adapted version of the Global Self-Worth subscale of the Self-Perception Profile for Adolescents (Wichstrøm, 1995), demonstrated evidence of convergent validity. Evidence of criterion-related validity was not reported.

Strengths and limitations. The scale is brief in its selection of items because each item assesses a different component of addiction. As the scale was adapted for use in a sample of Dutch male adolescents, its generalizability to other samples is unknown. Because validity of the instrument was only implicitly assessed, further psychometric validation would be necessary before being able to draw any conclusions about its robustness and utility.

\section{Compulsive Pornography Consumption (CPC) scale}

The Compulsive Pornography Consumption (CPC; Noor, Rosser \& Erickson, 2014) scale is a five-item scale that assesses "compulsive pornography consumption" (p.245). The 
items on the CPC are based on definitions of obsessive-compulsive disorder in the DSM-5, and have two factors: preoccupation and compulsivity. Sample items include: "I thought of pornography when I was trying to focus on other things" (preoccupation component) and "I watched pornography even though I did not want to" (compulsivity component), rated on a 7point scale, from 'never' to 'very frequently'. The CPC assesses five addiction components including salience, impaired control, mood modification, intrapsychic conflict, and sex life conflict. No cut-off score was provided to differentiate problematic from non-problematic pornography users.

Sample. The CPC was validated on a sample of men who have sex with men.

Reliability. The CPC full scale has good internal consistency $(\alpha=.85)$, while both subscales have fair internal consistency: preoccupation $(\alpha=.74)$ and compulsivity $(\alpha=.78$ 0.79). However, temporal stability of the instrument was not reported.

Validity. The factor structure of the CPC was derived from exploratory and confirmatory factor analyses. The CPC demonstrated evidence of convergent validity, being positively correlated with negative affect as assessed by a short form of the Positive and Negative Affect Schedule (PANAS; Thompson, 2007), the Compulsive Sexual Behavior Inventory (CSBI; Coleman, Miner, Ohlerking \& Raymond, 2001) and internalized homonegativity (Smolenski, Diamond, Ross \& Rosser, 2010), while being negatively correlated with positive affect as assessed by the short form of the PANAS (Thompson), social desirability (Strahan \& Gerbasi, 1972), and sexual self-esteem as assessed by the sexual confidence and sexual satisfaction subscales of the Multidimensional Sexuality Questionnaire (Snell, Fisher \& Walters, 1993). Also, participants with heavy alcohol use and multiple sex partners had higher CPC scores, providing further evidence of convergent validity. Evidence of criterion-related validity of the CPC was demonstrated by the finding that participants who reported viewing more than 7 hours of sexually explicit material a week had higher CPC scores compared to participants who reported less than one hour of viewing sexually explicit material a week.

Strengths and limitations. The CPC is brief and easy to administer and has robust psychometric properties. Nonetheless, a disadvantage of being brief is that it has a narrower coverage of addiction components $(n=5)$. One item on the CPC, "I could only have an orgasm when watching pornography" stands out as being ambiguous, as it does not primarily assess 'compulsivity' though it falls under the compulsivity subscale. Rather, it appears to assess negative effects on sex life brought about through dependence on pornography for sexual arousal. Thus, while this item does provide richer information about the respondent, the 
extent to which it assesses 'compulsivity' is debatable. Also, the CPC was validated in a sample of men who have sex with men and needs to be validated in more diverse samples.

\section{Cyberporn Compulsivity Scale (CCS)}

The Cyberporn Compulsivity Scale (CCS; Abell, Steenbergh \& Boivin , 2006) is a 4item scale that assesses "sexual behaviors relating to internet-based pornography" (p.167). The items on the CCS are based on the Sexual Compulsivity Scale (Kalichman \& Rompa, 1995), which defines sexual compulsivity as an "insistent, repetitive, intrusive and unwanted urge to perform specific acts often in ritualized or routinized fashions" (p.587). The CCS has a single factor, with sample items including "my sexual appetite for cyberporn has gotten in the way of my relationships" and "because of cyberporn, my sexual thoughts and behaviors are causing problems in my life", rated on a 4-point scale, from 'not at all like me' to 'very much like me'. The CCS assesses three addiction components, namely craving, interpersonal conflict, and general life conflict. No cut-off score was provided to differentiate problematic from non-problematic pornography users.

Sample. The CCS was adapted for use with a sample of male college students.

Reliability. Internal consistency of the full scale was good $(\alpha=.0 .80)$, but temporal stability of the scale was not reported.

Validity. Validation of the instrument was not described in the study.

Strengths and limitations. The CCS is brief and easy to administer but has a narrow coverage of addiction components $(n=3)$. Also, the CCS needs more comprehensive psychometric validation before any conclusions can be drawn about its psychometric robustness and utility.

\section{Cyber Pornography Addiction Test (CYPAT)}

The Cyber Pornography Addiction Test (CYPAT; Caccioppo et al., 2018) is an 11item scale that was designed to screen for internet pornography addiction. The items on the CYPAT were based on various models of addiction. The CYPAT has a single factor and sample items include "sometimes, I feel unable to control the watching of porn sites" and “porn sites make me feel less alone", rated on a 5-point scale, from 'never' to 'always'. The CYPAT assesses eight addiction components, namely salience, impaired control, relapse, mood modification, interpersonal conflict, general life conflict, sex life conflict, and use despite harm. No cut-off score was provided to differentiate problematic from nonproblematic pornography users.

Sample. The CYPAT was validated on samples of men and women. 
Reliability. The CYPAT has excellent internal consistency $(\alpha=.96)$. However, temporal stability of the instrument was not reported.

Validity. The single-factor structure of the CYPAT was derived from exploratory and confirmatory factor analyses. The scale demonstrated evidence of convergent validity, being positively correlated with Twenty-Item Toronto Alexithymia Scale (TAS-20; Bagby Taylor \& Parker, 1994; Bagby, Parker \& Taylor, 1994), and several factors of the Family Adaptability and Cohesion Evaluation Scale (FACES-IV; Olson, 2011). Also, the CYPAT has a strong correlation with the CPUI (Grubbs et al., 2010), providing evidence for criterionrelated validity.

Strengths and limitations. The CYPAT is a brief scale with robust psychometric properties. A major strength of the CYPAT is that it has a wide breadth of coverage of addiction components $(n=9)$. It is one of only two scales in this review that assesses the 'use despite harm' component, which is a component that is assessed by both HD and CSBD criteria. The CYPAT needs further validation in a clinical sample before the extent of its utility can be known.

\section{The Cyber Pornography Use Inventory (CPUI) and Cyber Pornography Use Inventory-9 (CPUI-9)}

The Cyber Pornography Use Inventory (CPUI; Grubbs, Sessom, Wheeler \& Volk, 2010) and the Cyber Pornography Use Inventory-9 (CPUI-9; Grubbs, Volk, Exline \& Pargament, 2015) are variations of the same instrument. The CPUI-9 is intended to be a refined version of the original CPUI. The CPUI was modelled on the Internet Sex Screening Test (ISST; Delmonico \& Miller, 2003), which was itself based on Schneider's (1994) model of addictive behavior, and thus the CPUI-9 shares the same theoretical framework as well.

CPUI. The CPUI is a 31-item scale that was designed to assess online pornography addiction. The CPUI has three factors: addictive patterns, guilt regarding online pornography use, and online sexual behavior-social. Sample items include: "at times I try to arrange my schedule so that I will be able to be alone in my room to view pornography" (addictive patterns factor), "I feel ashamed after viewing pornography online" (guilt regarding online pornography use), and "I have increased the risks I take online (give out name and phone number, meet people offline, etc.) (online sexual behavior-social factor), rated on a 5-point scale, from 'never' to 'always', or a 7-point scale, 'strongly disagree' to 'strongly agree'. The CPUI assesses eleven addiction components, namely salience, impaired control, withdrawal, tolerance, craving, interpersonal conflict, intrapsychic conflict, 
educational/occupational conflict, sleep conflict, general life conflict and hiding/secrecy/deception.

Sample. The CPUI was validated on students at a Christian university.

Reliability. The three subscales of the CPUI have good internal consistency addictive patterns $(\alpha=.89)$, guilt regarding online pornography use $(\alpha=.83)$ and online sexual behavior-social $(\alpha=.84)$. Internal consistency for the full scale, and temporal stability for the scale was not reported.

Validity. The factor structure of the CPUI was derived from principal components analysis. Convergent/discriminant validity or criterion-related validity was not reported.

Strengths and limitations. A major strength of the CPUI is that it assesses a very broad range of addiction components $(n=11)$, but its length at 31 items is its main limitation. Also, the CPUI was designed to "make allowances for the effect that religiosity might have on an individual's self-perceived levels of addiction" (p.111), with particular interest in guilt that religious individuals may feel as a result of their pornography use. As the developers had clinical implications in mind (with religious populations in particular) when designing the instrument (in particular the Guilt subscale), the suitability of using the CPUI with nonreligious populations is uncertain.

CPUI-9. The CPUI-9 is a 9-item scale that was designed to assess "problematic pornography use and perceived addiction to internet pornography" (p.21). The CPUI-9 has three factors: perceived compulsivity, access efforts, and emotional distress. Sample items include "I feel unable to stop my use of online pornography" (perceived compulsivity subscale), "I have put off important priorities to view pornography" (access efforts subscale), and "I feel ashamed after viewing pornography online" (emotional distress subscale), rated on a 7-point scale, from 'not at all' to 'extremely'. The CPUI-9 assesses six addiction components, including salience, impaired control, craving, interpersonal conflict, conflict: intrapersonal, and general life conflict.

Sample. The CPUI-9 was validated in more diverse samples compared to the CPUI with samples of male and female college students and clinical sample.

Reliability. The internal consistency of the CPUI-9 ranges from fair to good - CPUI full scale ( $\alpha=.75-.89)$, perceived compulsivity ( $\alpha=.81-.89)$, access efforts $(\alpha=.75-0.81)$, and emotional distress $(\alpha=.74-.83)$.

Validity. The factor structure of the CPUI-9 was derived with exploratory and confirmatory factor analyses. The CPUI-9 demonstrated evidence for convergent validity. The CPUI full scale has positive correlations with the Sexual Compulsivity Scale (Kalichman 
\& Rompa, 1995), perceived stress (Cohen, Kamarck \& Mermelstein, 1983), state anxiety (Spielberger, Gorsuch, Lucene, Vagg \& Jacobs, 1983), and an aggregated measure of psychological distress. The CPUI full scale also demonstrates evidence of criterion-related validity, being positively correlated to amount of time spent viewing pornography.

Strengths and limitations. The CPUI-9 has robust psychometric properties and has a more diverse validation sample compared to the CPUI. It is brief which facilitates ease of administration, but breadth of coverage of addiction components $(n=6)$ is reduced compared to the CPUI. Some items from the 'Guilt' subscale of the CPUI were retained to form the Emotional Distress subscale of the CPUI-9, but with an intended focus on "negative affect associated with pornography use rather than feelings of guilt or shame directly" (Grubbs et al., 2015, p. 9). It is important to highlight that questions surrounding the use of the Emotional Distress subscale have nonetheless been raised in the literature, mainly about the possibility of the subscale inflating full scale scores of individuals who morally disapprove of pornography (Brand, Antons, Wegmann \& Potenza, 2018; Fernandez, Tee \& Fernandez, 2017), which the leading author of the CPUI-9 has since responded to at length (see Grubbs, Perry, Wilt \& Reid, 2019b).

\section{Deficient Self-Regulation Scale, Habit Strength Scale, and Negative Consequences Scale}

The Deficient Self-Regulation Scale, Habit Strength Scale, and Negative Consequences Scale (Sirianni \& Vishwanath, 2016) are scales that were developed as part of the same study, to test a model of problematic pornography use from a socio-cognitive perspective. The instruments are based on La Rose's (2003) social cognitive model of unregulated media behavior and La Rose and colleagues' (2010) socio-cognitive model of problematic internet use and defines problematic pornography use from a deficient selfregulation perspective as opposed to an addiction perspective.

The Deficient Self-Regulation Scale is a seven-item scale that was designed to assess deficient self-regulation related to pornography use. The scale has a single factor, with sample items such as "I struggle to control my desire to view online pornography", rated on a 5-point scale from 'strongly disagree' to 'strongly agree'. The scale assesses six addiction components, including salience, impaired control, withdrawal, relapse, mood modification, and intrapsychic conflict.

The Habit Strength Scale is a five-item scale that was designed to assess habit strength related to pornography use. The scale has a single factor, with sample items such as "Viewing pornography is part of my usual routine", rated on a 5-point scale from 'strongly 
disagree' to 'strongly agree'. The scale assesses two addiction components (i.e., impaired control and withdrawal).

The Negative Consequences Scale is a seven-item scale that was designed to assess negative consequences resulting from pornography use. The scale has a single factor, with sample items such as "The online pornography that I view has negatively affected my school and/or job", rated on a five-point scale from 'strongly disagree' to 'strongly agree'. The scale assesses four addiction components related to conflict from different dimensions (i.e., interpersonal conflict, financial conflict, educational/occupational conflict, and general life conflict.

Sample. All three scales were validated on samples of male and female college students.

Reliability. The scales have good to excellent internal consistency - Deficient SelfRegulation Scale $(\alpha=.92)$, Habit Strength scale $(\alpha=.88)$, and Negative Consequences scale $(\alpha=.94)$. Temporal stability for all three scales were not reported.

Validity. Factor analysis was conducted on all the items in the model, of which these three scales make up 'subscales' or separate 'factors', though the scales are not part of a larger scale per se. Evidence for convergent and discriminant validity for all three scales were provided by demonstrating that the average variance extracted for each scale exceeds 0.50 , and that the diagonal values are significantly higher than the off-diagonal values in the corresponding rows and columns. Further evidence of convergent validity was demonstrated by correlations between the three scales.

Strengths and limitations. Further validation of these scales was not provided, as they were adapted for the purpose of testing their hypothesized model. However, if validated more comprehensively, these scales may be useful in that they conceptualize problematic pornography use from a social-cognitive perspective, and thus provide a unique conceptualization of problematic pornography use. This may have useful applications especially to individuals on the sub-clinical end of the spectrum struggling with aspects of their pornography use without necessarily facing serious negative life consequences.

\section{Adaptations of the Internet Addiction Test}

The Internet Addiction Test-Sex (IAT-Sex; Brand et al., 2011) and the French version of the Short Internet Addiction Test adapted to online sexual activities (S-IAT-Sex; Wéry, Burnay, Karila, \& Billieux, 2015) are both variations of the same test. The S-IAT-Sex is intended to be a shortened version of the IAT-Sex. Both instruments were adapted from the 
original Internet Addiction Test (Young, 1998; Widyanto \& McMurran, 2004), and based on Young's (1998) model of internet addiction applied to online sexual behavior.

Internet Addiction Test-Sex (IAT-sex). The IAT-Sex is a 20-item scale that was adapted to assess "subjective complaints in everyday life due to online sexual activities and potential symptoms of cybersex addiction" (p.373). The IAT-Sex has six factors (i.e., salience, excessive use, neglecting work, anticipation, lack of control, and neglecting social life). The IAT-Sex assesses ten addiction components, including salience, impaired control, withdrawal, relapse, mood modification, interpersonal conflict, educational/occupational conflict, sleep conflict, household/hobby conflict, and hiding/secrecy/deception. No cutoff score to differentiate between problematic or non-problematic users of pornography was provided.

Sample. The IAT-Sex was adapted for use with a sample of heterosexual men.

Reliability. The scale demonstrated good internal consistency $(\alpha=.84)$, but temporal stability was not reported.

Validity. The factor structure of the IAT-Sex was not confirmed with factor analysis. Evidence of convergent validity of the IAT-Sex was provided by demonstrating positive correlations with obsessive-compulsiveness, interpersonal sensitivity, depression, anxiety, phobic anxiety, paranoid ideation, psychoticism, and the global severity index on the Symptom Check List (SCL-90-R; Franke, 2002), and with the IAT. Further evidence of convergent validity was provided by demonstrating that scores on the IAT-Sex were predicted by sexual arousal ratings and usage of online sex applications. Criterion-related validity was demonstrated by IAT-Sex scores being predicted by time spent on online sex sites.

Strengths and limitations. A major strength of the IAT-Sex is that it has a very broad coverage of addiction components $(n=11)$. However, because the items were adapted from an the Internet Addiction Test, the way the items have been phrased are restricted by its original manner of phrasing. The factor structure of the IAT-Sex was not validated using factor analysis and thus needs further validation in future studies.

Short French Internet Addiction Test-Sex (s-IAT-Sex). The French version of the sIAT-Sex is a 12-item scale that assesses "subjective complaints in everyday life due to online sexual activities and potential symptoms of problematic online sexual activities" (p.3). There are two factors: loss of control/time management, and craving/social problems. Sample items include: "How often do you find that you stay on internet sex sites longer than you intended?" and "How often do you choose to spend more time on internet sex sites over 
going out with others?', rated on a five-point scale, from 'never' to 'always'. The s-IAT-Sex assesses ten addiction components: salience, impaired control, withdrawal, relapse, mood modification, conflict: relationships, educational/occupational conflict, sleep conflict, household/hobby conflict, and hiding/secrecy/deception. No cutoff score to differentiate between problematic or non-problematic users of pornography was provided.

Sample. The S-IAT-Sex was validated on a sample of French-speaking men,

Reliability. The scale demonstrated fair to good internal consistency - full scale $(\alpha=.88)$, loss of control/time management $(\alpha=.87)$ and craving/social problems $(\alpha=.76)$. Temporal stability of the instrument was not reported.

Validity. The two-factor structure of the scale was derived using confirmatory factor analysis. Evidence of convergent validity was demonstrated by the s-IAT-Sex having positive correlations with PATHOS (Carnes et al., 2012), a brief screening instrument for sexual addiction. Also, evidence for criterion-related validity was demonstrated by correlations with time spent online for online sexual activities and frequency of online sexual activities.

Strengths and limitations. An advantage of the s-IAT-Sex is its brevity, and despite being short, it has decent breadth of coverage of addiction components $(n=9)$. Being an adapted test, the way the items have been rephrased to focus on 'internet sex sites' may not account for other ways pornography users may access online pornography without needing to spend time on specific websites (e.g., downloading pornography from peer-to-peer networks).

\section{Internet Sex Screening Test (ISST)}

The Internet Sex Screening Test (ISST; Delmonico \& Miller, 2003) is a 25-item scale that was designed to "help individuals determine if their internet sexual behavior has become clinically problematic" (p.262). The ISST is based on Schneider's (1994) model of addictive behavior. The ISST has five factors: online sexual compulsivity, online sexual behaviorsocial, online sexual behavior-isolated, online sexual spending, and interest in online sexual behavior. Sample items include: "Internet sex has sometimes interfered with certain aspects of my life" (online sexual compulsivity), "I have participated in sexually related chats" (online sexual behavior-social), "I have masturbated while on the internet" (online sexual behavior-isolated), "I have purchased sexual products online" (online sexual spending), and "I have some sexual sites bookmarked" (interest in online sexual behavior), answered on a dichotomous 'yes'/'no' scale. The ISST assesses nine addiction components, including salience, impaired control, withdrawal, tolerance, mood modification, intrapsychic conflict, financial conflict, general life conflict, and hiding/secrecy/deception. Cutoff scores are 
provided to interpret the ISST: $<8$ low risk, 9-18 at risk, and $>19$ high risk, although these thresholds have not been validated.

Reliability. The internal consistency of the subscales of the ISST range from below an acceptable threshold to good. The Online Sexual Compulsivity subscale has good internal consistency $(\alpha=.86)$, the Online Sexual Behavior-Social $(\alpha=.78)$ and Online Sexual BehaviorIsolated ( $\alpha=$.73) subscales have fair internal consistency, while internal consistency for the Online Sexual Spending subscale $(\alpha=.61)$, and the Interest in Online Sexual Behavior subscale $(\alpha=.51)$ were below the acceptable threshold of .70. Temporal stability was not reported.

Validity. Validation of the factor structure of the scale with factor analysis was not reported. Evidence for convergent/discriminant validity was not provided. Criterion-related validity was demonstrated by all subscale scores of the ISST being significantly higher for sexually compulsive participants (as measured by the Sexual Addiction Screening TestAbbreviated adapted from the Sexual Addiction Screening Test [SAST; Carnes, 1989) compared to non-sexually compulsive participants.

Strengths and limitations. A strength of the ISST is that it was validated on a large sample of men and women $(\mathrm{N}=6088)$ and has a fairly wide coverage of addiction components $(n=9)$. However, two subscales of the ISST (Online Sexual Spending and Interest in Online Sexual Behavior) have issues with its reliability. Furthermore, in reviewing each item, it was determined that 15 out of 25 items on the ISST simply assess the incidence of different sexual behaviors while not necessarily assessing problematic aspects of these behaviors. For example, items such as "I have masturbated while on the internet", "I have searched for sexual material through an internet search tool" and "I have purchased sexual products online" refer to sexual behaviors that may not be problematic at all for many individuals. As such, content validity of the ISST is questionable when taking into account its purpose of assessing clinically problematic online sexual behavior. Overall, the ISST needs further psychometric validation before its utility can be determined.

\section{Passion Scale-Pornography}

The Passion Scale-Pornography (Rosenberg \& Kraus, 2014) is a 14-item scale that was adapted from the original Passion Scale (Vallerand, 2003), which was itself based on Vallerand's (2003) model of harmonious versus obsessive passion for liked activities. The instrument assesses "passionate attachment" for pornography. The scale has two factors: harmonious passion, and obsessive passion. The 'harmonious passion' subscale assesses the extent to which the activity is an important and well-integrated part of an individual's life, 
while the 'obsessive passion' subscale assesses potentially addictive patterns of behavior. Sample items on the obsessive passion subscale include "My mood depends on me being able to use porn", "I almost feel obsessed with using porn" and "When the urge is so strong, I cannot help myself from using porn", rated on a 7-point scale, from 'disagree completely' to 'agree completely'. The obsessive passion subscale assesses four addiction components including salience, impaired control, mood modification, and craving. No cutoff score to differentiate problematic from non-problematic users of pornography was provided.

Sample. The Passion Scale-Pornography was validated on a sample of male college students.

Reliability. Both subscales have fair internal consistency: Harmonious passion $(\alpha=.78)$ and Obsessive passion $(\alpha=.79)$. Internal consistency for the full scale was not provided. Temporal stability at a one-week interval was reported for both subscales: Harmonious passion $(\mathrm{r}=.76)$, and Obsessive passion $(\mathrm{r}=.86)$.

Validity. Confirmation of the factor structure of the scale using factor analysis was not reported. Evidence for convergent validity was demonstrated by both subscales being correlated with measures of sexual compulsivity (Kalichman \& Rompa, 1995), craving for pornography (Kraus \& Rosenberg, 2014), and compulsive internet use (Meerkerk et al., 2009). Evidence for discriminant validity was demonstrated by both scales not having a relationship with measures of non-sexual sensation seeking (Hoyle, Stephenson, Palmgreen, Lorch \& Donohew, 2002) or social desirability (Stöber, 2001). Evidence for criterion-related validity was demonstrated by the finding that most frequent users of pornography reporting significantly higher mean scores on both subscales compared to those who used less pornography each week.

Strengths and limitations. The Passion Scale-Pornography is useful in that it recognizes the need to differentiate between healthy and unhealthy 'passionate attachment' to pornography and in doing so refrains from pathologizing harmonious interest and passion for an activity such as viewing pornography. Additionally, it is able to determine when an individual's pornography use is starting to become problematic - if their scores on the 'obsessive passion' subscale are high. Overall, the scale has robust psychometric properties. However, it is limited in assessing addiction comprehensively because it has a narrow coverage of addiction components $(\mathrm{n}=4)$.

\section{Pornography Consumption Effects Scale, Pornography Consumption Effects Scale-}

\section{Revised, and Pornography Consumption Effects Scale Short-Form}


The PCES (Hald \& Malamuth, 2008), the PCES-R (Hald, Smolenski \& Rosser, 2012) and the PCES-Short-Form (PCES-SF; Miller, Kidd \& Hald, 2019) are variations of the same scale. The PCES is the original scale and the PCES-R and PCES-SF are its derivatives. The PCES itself was the fourth section of the 139-item Pornography Consumption Questionnaire, which initially comprised 64 items, but was later reduced to 47 items. The PCES is largely atheoretical in the manner that it approaches pornography use, and is based on sexuality and pornography use research. Consequently, it does not approach pornography use from a 'problematic' or 'addiction' perspective. Its goal is to explore the effects of pornography consumption, both positive and negative. The negative effects of pornography assessed by these scales arguably assess aspects of problematic pornography use.

PCES. The PCES has 47 items comprising nine factors. It assesses "self-perceived effects of hardcore pornography consumption on participants' sexual behaviors or sex life, attitudes towards sex, sexual knowledge, life in general, and attitudes towards and perceptions of the opposite gender" (p.616). Five of these factors (sex life, attitudes towards sex, sexual knowledge, perception and attitudes towards opposite gender and life in general) form a 'positive effects dimension'; while four of these factors (sex life, attitudes towards sex, perception and attitudes towards opposite gender, and life in general) form a 'negative effects dimension'. Sample items on the PCES include: “To what extent do you believe that your consumption of pornography has taught you new sexual techniques" (positive effects dimension) and "To what extent do you believe that your consumption of pornography has adversely affected your outlook on sex?" (negative effects dimension). The PCES assesses three addiction components: general life conflict, negative attitudes conflict, and sex life conflict.

Sample. The PCES was validated on a sample of male and female young adults. Reliability. The internal consistency of its subscales range from fair to excellent $(\alpha=.72-.91)$. Temporal stability of the scale was not reported.

Validity. The factor structure of the PCES was validated using principal axis factor analysis. Evidence for convergent validity of the PCES was demonstrated by the subscales within the positive effect dimension being correlated with each other, and the subscales within the negative effect dimension being correlated with each other. Evidence for discriminant validity of the PCES is demonstrated by the negative effect dimension not being correlated with the positive effect dimension. In terms of criterion-related validity, the negative effect dimension was correlated with pornography consumption. However, it is interesting to note that the correlation between the positive effect dimension and pornography 
consumption is much stronger than the correlation between the negative effect dimension and pornography consumption, suggesting that overall, participants in the sample found pornography consumption having more positive effects than negative effects. The authors suggest the possibility that this could be accounted for by the generally liberal mindset of their young Danish sample, although this needs to be validated and confirmed across more diverse samples.

PCES-Revised. The PCES-R is a seven-item scale that assesses "cognitive, affective and behavioral effects of pornography" (p.759). The PCES-R was reduced from the original 47 PCES items to seven items and is scored differently. The seven items are rated on two separate five-point scales: the first concerning the valence of the effect from $1=$ very bad, to $5=$ very good, and the second concerning the magnitude of the effect from $1=$ decreased to $5=$ increased. A single index is derived from scores, with -2 being a strong, negative effect, and 2 being a strong positive effect, with 0 indicating a neither positive nor negative effect. Sample content of the items included knowledge of sex acts, attitude towards sex, and interest in trying new sexual positions. The PCES-R assesses two addiction components (i.e., sex life conflict and negative attitudes conflict).

Sample. The PCES-R was validated on samples of men who have sex with men.

Reliability. The PCES-R demonstrated good internal consistency $(\alpha=.80)$, but temporal stability was not reported.

Validity. The single-factor structure of the scale was derived using exploratory and confirmatory factor analyses. Evidence of convergent validity was demonstrated by the instrument being positively correlated to positive affect as assessed by the short form of the PANAS (Thompson, 2007) and sexual self-esteem as assessed by the sexual confidence and sexual satisfaction subscales of the Multidimensional Sexuality Questionnaire (Snell et al., 1993). Evidence for discriminant validity was demonstrated by scores on the instrument being unrelated to negative affect as assessed by the short form of the PANAS (Thompson), social desirability (Strahan \& Gerbasi, 1972), and compulsive sexual behavior (Coleman et al., 2001). Temporal validity and criterion-related validity for the scale were not reported. As the validation sample was limited to men who have sex with men, generalizability beyond this population is unknown.

PCES-Short-Form. The PCES-SF is a 14-item scale and is a shortened version of the PCES. The PCES-SF has the same nine factors like the original PCES. The PCES-SF assesses three addiction components: negative attitudes conflict, sex life conflict, and general life conflict. 
Sample. The PCES-SF was validated in a sample of heterosexual men.

Reliability. The PCES-SF demonstrated excellent internal consistency for both the positive effect dimension $(\alpha=.91)$ and negative effect dimension $(\alpha=.91)$, while Spearman Brown coefficients for all subscales ranged from .79 to .86 .

Validity. The factor structure of the PCES-SF was confirmed using confirmatory factor analysis. Evidence for convergent validity of the scale was demonstrated by being positively correlated with the long-form version of the PCES. Evidence for discriminant validity was provided by the scale showing no relationship with a measure of social desirability.

Strengths and limitations. Overall, the PCES and its derivatives have robust psychometric properties. There is an advantage in approaching pornography use from a neutral perspective in preventing participants from being primed with the idea that their pornography use may be problematic if items only include negative components of pornography use. There are benefits of accumulating additional raw data from participants to investigate that even if participants are experiencing negative effects in their pornography use, whether they are also experiencing positive effects. However, these scales are limited in their ability to assess more addiction components beyond negative effects on life in general, attitudes, and sex life. As such the scales have limited utility for participants with addictive or compulsive pornography use.

\section{Pornography Consumption Inventory}

The Pornography Consumption Inventory (PCI; Reid, Li, Gilliland, Stein \& Fong, 2011 ) is a 15-item scale that assesses "motivations for pornography use among hypersexual men" (p.359). Conceptually, the PCI is based on empirical and clinical findings of HD (Kafka, 2010). There are four factors: sexual curiosity, emotional avoidance, excitementseeking, and sexual pleasure. Of particular relevance to problematic pornography use is the emotional avoidance subscale, with sample items such as "I turn to [pornography] when I'm feeling down, sad or lonely" and "I use [pornography] to avoid feeling uncomfortable or unpleasant emotions", rated on a 5-point scale, from 'never like me' to 'very often like me'. The other three subscales of the PCI arguably explore more neutral and non-problematic motivations for pornography, although Item 5 (pertaining to the excitement seeking subscale; "I use [pornography] to escape into a fantasy world") could be argued to be assessing the 'mood modification' component of addiction. Overall, the PCI only assesses the mood modification component. Nonetheless, the entire PCI was constructed with a specific 
population in mind - hypersexual men - and as such, results from all four subscales have the potential to be of interest to researchers and clinicians.

Sample. The PCI was validated on samples of men who self-identified as addicted to pornography, and men seeking treatment for hypersexual behavior.

Reliability. The PCI demonstrates fair to excellent internal consistency for the full scale $(\alpha=.83-.93)$ and its subscales: emotional avoidance $(\alpha=.85-.95)$, sexual curiosity $(\alpha=.87$ $.89)$, excitement-seeking ( $\alpha=.73-.85)$, and sexual pleasure $(\alpha=.71-.90)$. The PCI full scale demonstrated temporal stability at a two-week interval of $r=.86$.

Validity. The factor structure of the PCI was derived using exploratory and confirmatory factor analyses. Evidence of convergent validity was demonstrated through the emotional avoidance subscale being positively correlated to excitement-seeking and sexual pleasure subscales of the PCI, to the loneliness, anxiety, depression, impulsiveness, vulnerability, and fantasy subscales of the NEO Personality Inventory-Revised (NEO-PI-R; Costa \& McCrae, 1992) while being negatively correlated to positive emotions subscale of the NEO-PI-R. Also, the sexual curiosity subscale was shown to be positively correlated to impulsiveness and fantasy subscales of the NEO-PI-R.

Evidence of discriminant validity was demonstrated by the emotional avoidance subscale being unrelated to the sexual curiosity subscale of the PCI, and being negatively related to Positive Emotions subscale of the NEO-PI-R. Discriminant validity was also demonstrated by the sexual curiosity subscale being unrelated to the loneliness, anxiety, depression, vulnerability, positive emotions, and self-discipline subscales of the NEO-PI-R. Finally, the sexual pleasure subscale was unrelated to loneliness and positive emotions subscales of the NEO-PI-R.

In terms of criterion-related validity, frequency of pornography use was correlated with emotional avoidance and sexual pleasure subscales. Additionally, the full scale and subscales of the PCI were correlated with the HBI (Reid et al., 2011a). Finally, participants who reported spending more than one hour viewing pornography per week scored higher on Emotional Avoidance compared to participants who reported spending less than one hour per week viewing pornography.

Strengths and limitations. The PCI is the only instrument in the present review that specifically examines motivations for pornography use and is a potential source of rich information about participants. However, only one component of addiction (mood modification) is assessed and as such cannot be used for a comprehensive assessment of addiction symptoms. While the PCI has good psychometric properties, it was validated on 
samples of men with hypersexual disorder, therefore, generalizability to non-clinical samples is unknown.

\section{Pornography Craving Questionnaire (PCQ)}

The Pornography Craving Questionnaire (PCQ; Kraus \& Rosenberg, 2014) is a 12item scale that assesses craving for pornography. The PCQ is theoretically based on models of addiction of which craving is an element. The PCQ has a single factor (i.e., subjective craving for pornography). Sample items include "I have an urge to watch porn right now" and "If I watched porn now I would have difficulty stopping", rated on a 7-point scale from 'disagree completely' to 'agree completely'. Although described as a craving questionnaire, the PCQ assesses four addiction components: salience, impaired control, craving, and mood modification.

Sample. The PCQ was validated on samples of male college students.

Reliability. The PCQ demonstrated excellent internal consistency $(\alpha=.91)$ and testretest reliability of .82 at one-week follow-up.

Validity. The single-factor structure of the PCQ was derived with principal components analysis. Evidence of convergent validity was demonstrated by the PCQ being positively correlated to passionate attachment for pornography (Rosenberg \& Kraus, 2014), sexual compulsivity (Kalichman \& Rompa, 1995), and compulsive internet use (Meerkerk et al., 2009). Evidence for discriminant validity was demonstrated by the PCQ being unrelated to non-sexual sensation-seeking (Hoyle et al., 2002). Evidence for criterion-related validity was provided by the PCQ being related to frequency of weekly pornography use and predicting frequency of pornography use in the following week.

Strengths and limitations. Overall, the PCQ appears to have good psychometric properties. It has promising utility for providing greater depth of information regarding one specific addiction component (i.e., craving), but at the cost of sacrificing breadth of coverage of addiction components $(\mathrm{n}=4)$

\section{Pornography Use Scale (PUS)}

The Pornography Use Scale (PUS; Szymanski \& Stewart-Richardson, 2014) is a 14item scale that assesses men's pornography use in terms of frequency of use and problematic pornography use. The PUS has an addiction theoretical framework and is based on research on sexual and substance addictions. The scale has two factors: frequency of use and problematic pornography use. Sample items include, "How frequently do you view sexual (sic) explicit materials/pornography on the internet" (frequency of use subscale) rated on 4point/5-point scales depending on the item, and "My use of sexually explicit 
materials/pornography is a problem in my romantic relationship currently" (problematic pornography subscale), rated on a 5-point scale, from 'strongly agree' to 'strongly disagree'. The PUS assesses four addiction components: impaired control, interpersonal conflict, intrapsychic conflict, and general life conflict.

Sample. The PUS was validated on a sample of male heterosexuals which included college-age students.

Reliability. The PUS demonstrated good to excellent internal consistency for its full scale $(\alpha=.94)$, frequency of use subscale $(\alpha=.88)$, and problematic use subscale $(\alpha=.91)$. Temporal stability was not reported.

Validity. The factor structure of the PUS was derived from exploratory and confirmatory factor analyses. Evidence of convergent validity was demonstrated by the problematic use subscale being related to greater gender role conflict (O'Neil, Helms, Gable, David \& Wrightsman, 1986), avoidant and anxious attachment styles (Brennan, Clark \& Shaver, 1998), poorer relationship quality (Spanier, 1976), and less sexual satisfaction (Snell et al., 1993). Also, the problematic use subscale was related to the online sexual compulsivity subscale of the ISST (Delmonico \& Miller, 2003). Evidence for discriminant validity was demonstrated by the full scale being negatively related to relationship length, while being unrelated to social desirability (Reynolds, 1982). In terms of criterion-related validity, the problematic use subscale was related to frequency of pornography use, as measured by the frequency of pornography use subscale.

Strengths and limitations. The PUS has good psychometric properties. The main contribution of the PUS is that it provides a good measure for investigating frequency of pornography use in a standardized fashion with its frequency of use subscale. However, the PUS is limited in its ability to assess a broad range of addiction components, assessing only four components.

\section{Problematic Pornography Consumption Scale (PPCS)}

The Problematic Pornography Consumption Scale (PPCS; Böthe et al., 2017) is an 18-item scale that assesses "problematic online pornography use" (p.1) and has Griffiths' (2005) components model of addiction as its theoretical framework, where items were developed for each component. Corresponding to the six components, there are six factors: salience, mood modification, conflict, tolerance, withdrawal and relapse. Sample items include "I felt that porn is an important part of my life" (salience), "Watching porn got rid of my negative feelings" (mood modification) and "I felt that I had to watch more and more porn for satisfaction" (tolerance), rated on a 7-point scale from 'never' to 'all the time'. The 
PPCS assesses nine components of addiction, namely salience, tolerance, withdrawal, mood modification, relapse, household/hobby conflict, general life conflict, and sex life conflict. The authors provided an optimal cutoff of 76 (out of 126) to be classified as a problematic pornography user.

Sample. The PPCS was validated on a sample of men and women.

Reliability. The PPCS has range of fair to excellent internal consistency - full scale $(\alpha=.93)$, salience $(\alpha=.77)$, mood modification $(\alpha=.84)$, conflict $(\alpha=.71)$, tolerance $(\alpha=.78)$, withdrawal $(\alpha=.86)$ and relapse $(\alpha=.86)$. Temporal stability for the instrument was not reported.

Validity. Factor structure of the PPCS was confirmed using confirmatory factor analysis. Evidence of convergent validity was demonstrated by the PPCS being correlated with frequency of masturbation, and negatively correlated with satisfaction with sexual life. Criterion-related validity was demonstrated by the PPCS being correlated with time spent viewing pornography per occasion, frequency of reading online pornographic stories, online pornography picture viewing, online pornography video viewing, and frequency of pornography consumption during masturbation.

Strengths and limitations. A strength of the PPCS is that it has a clear theoretical framework to guide its construction, with factor analyses confirming the factors corresponding to the six addiction components. Furthermore, this is the only instrument in the present review that explicitly assesses the 'tolerance' component and thus may be useful to researchers or clinicians who wish to obtain specific information related to tolerance in respondents. However, as comprehensive as the PPCS aims to be, it suffers from a lack of breadth of coverage of important dimensions of conflict. For the three items assessing conflict, only sex life conflict, and conflict in terms of hobbies/leisure activities are assessed. However, conflict in terms of interpersonal relationships and conflict in terms of education/occupation, both major indicators of conflict in addiction, was not assessed. Thus, potentially useful information may not be captured by the scale in its current form. Nonetheless, a strength of the PPCS is that it is the only instrument in the present review to provide a validated cutoff score to differentiate between problematic and non-problematic users of pornography.

\section{Problematic Pornography Use Scale (PPUS)}

The Problematic Pornography Use Scale (PPUS; Kor et al., 2014) is a 12-item scale that assesses problematic pornography use and is based on models describing core features of addiction. The PPUS has four factors: distress and functional problems, excessive use, 
control difficulties, and use for escape/avoid negative emotions. Sample items include "Using pornography has created significant problems in my personal relationships with other people, in social situations, at work or in other important aspects of my life" (distress and functional problems subscale) and "I have been unsuccessful in my efforts to reduce or control the frequency I use pornography in my life" (control difficulties), rated on a 6-point scale, from 'never true' to 'almost always true'. The PPUS assesses eight addiction components, including salience, impaired control, relapse, mood modification, interpersonal conflict, educational/occupational conflict, general life conflict, and use despite harm.

Sample. The PPUS was validated on samples of male and female college students.

Reliability. The PPUS has internal consistency ranging from fair to excellent for full scale and subscales $(\alpha=.75-.93)$. Temporal stability of the instrument was not reported.

Validity. Factor structure of the PPUS was supported by principal components analysis and confirmatory factor analysis. Evidence for convergent validity was demonstrated by the scale being related to the CPUI (Grubbs et al., 2010), subscales of the PCI (Reid et al., 2011b), poorer self-esteem (Rosenberg, 1965), sexual behavior consequences as assessed by the HBCS (Reid et al., 2012), attachment insecurities (Brennan et al., 1998), hypersexual disorder (Reid et al., 2012a; Reid et al., 2012b) , internet addiction (Young, 1998), and traumatic events (Nijenhuis, Van der Hart \& Vanderlinden, 1999). Evidence for discriminant validity was demonstrated through the finding that the PPUS has weaker correlations with internet addiction and gambling addiction (Winters, Stinchfield \& Fulkerson, 1993) compared to hypersexual disorder. In terms of criterion-related validity, the PPUS was positively correlated with frequency of pornography use.

Strengths and limitations. The PPUS has robust psychometric properties. However, some of the items on the PPUS are lengthy and might need further clarification from the respondent to provide more information (e.g., Item 1: "Using pornography has created significant problems in my personal relationships with other people, in social situations, at work, or in other important areas of my life"). While this manner of constructing the item allows for an exhaustive exploration of possible life areas that have been affected by pornography, the item itself does not provide clear information about which area of life has been affected. Nonetheless, the PPUS has excellent coverage of addiction components $(n=8)$ and is one of only two instruments in the present review to assess the 'use despite harm' component, which is an addiction component assessed by both HD and CSBD diagnostic criteria.

\section{Discussion}


The aim of the present study was to conduct a systematic review on psychometric instruments assessing problematic pornography use. Twenty-two psychometric instruments assessing at least some aspect of problematic pornography use were reviewed.

\section{Conceptualizations of problematic pornography use}

The instruments reviewed had different theoretical conceptualizations of problematic pornography use, ostensibly due to the lack of consensus at present in the field about how best to operationalize problematic sexual behavior. Other than an addiction framework, the instruments approached problematic pornography use from varying perspectives - three from a social-cognitive perspective, three from an atheoretical and neutral perspective, two from a compulsive behavior perspective, and one from a hypersexual behavior perspective.

Nonetheless, addiction still emerged as the most influential theoretical model in conceptualizing problematic pornography use, as reflected in the finding that more than half of the instruments in this review were built on an addiction framework (13 out of 22). In the case of two scales (PPUS and PPCS) where the term 'problematic' was explicitly used to describe the construct, addiction was still the theoretical model guiding the content of the scales. It appears that in the literature, the term 'problematic' is arguably a placeholder for the term 'addiction' because researchers appear to be reluctant to use the term 'pornography addiction' in the absence of formal recognition of its validity as a disorder. Of the 12 instruments using addiction as their theoretical framework, it is interesting to note that only three scales used the term 'addiction' in their scale title. Two of these were adaptations based on scales for internet addiction (IAT-Sex and s-IAT-Sex), and only one was developed specifically for the purpose of assessing pornography addiction (CYPAT).

It should also be noted that some authors in their scale development (i.e., the CPUI-9; Grubbs et al., 2015) use the term "perceived addiction to pornography" as opposed to "addiction to pornography" in defining the construct being assessed. This implies that there might sometimes be a disparity between an individual's self-perception of addiction and the actual reality. The potential for overpathologizing sexual behaviors has indeed been recognized to be a major concern when assessing problematic sexual behaviors in general, as reflected in the diagnostic guidelines for CSBD proposed for ICD-11 (Kraus et al., 2018). Kraus et al. suggest that individuals who identify as being 'sex addicts' or 'porn addicts' might not necessarily "exhibit clinical characteristics of the disorder" (p.109), although they may perceive themselves as such. Kraus et al. list other factors that might lead to false positives in diagnosis (e.g., high levels of sex drive or interest without evidence of impaired control, or distress related to moral judgments about sexual impulses, urges, or behaviors). 
Therefore, a practical implication for problematic pornography use assessment would be that, taking into account the possibility of specific individuals overpathologizing their own behavior, items focusing on objective behavior patterns (e.g., "I have had many unsuccessful attempts to reduce my pornography use") would likely have greater validity compared to items focusing on belief or perception (e.g., "I believe I am addicted to pornography").

\section{Assessment of addiction components}

Despite the varying theoretical orientations, the instruments had significant overlaps in components of addiction they assessed. The most frequently assessed components of addiction were impaired control, salience, mood modification, interpersonal conflict, and general life conflict. If taking a majority consensus view across all the instruments included in the present review, these five symptoms appear to represent the 'core' criteria for problematic pornography use. This finding is unsurprising because these symptoms are core features of addiction models (Griffiths, 2005; Shaffer, 1999) and HD and CSBD diagnostic criteria.

Other common components of addiction had significantly less inclusion by the instruments: educational/occupational conflict, intrapsychic conflict, withdrawal, tolerance, craving, and use despite harm. Educational/occupational conflict and intrapsychic conflict, while not infrequently assessed, were not as commonly assessed as the top five components. This finding is surprising, when taking into account that 'distress' and 'impairment in educational or occupational functioning' are typically listed as part of diagnostic criteria for disorders, HD and CSBD included.

Furthermore, while withdrawal and tolerance form key parts of addiction models (Griffiths, 2005), they were not assessed as frequently by the instruments relative to the other core criteria. This might be due to withdrawal and tolerance not being universally accepted in the field as necessary components of behavioral addictions (e.g., Starcevic, 2016). It is also worth noting that HD and CSBD diagnostic criteria do not include withdrawal and tolerance as they are not based on an addiction framework. Nonetheless, an interesting finding was that tolerance was assessed much less frequently than withdrawal by the instruments - only one scale explicitly assessed tolerance with regards to pornography use. This is not necessarily reflective of the extant empirical research on both these components in relation to pornography use. While withdrawal has been explored relatively substantially with other problematic behaviors (e.g., gambling - Blaszczynski, Walker, Sharpe \& Nower, 2008; Cunningham-Williams, Gattis, Dore, Shi \& Spitznagel, 2009; gaming - Kaptsis, King, Delfabbro, \& Gradisar, 2016a, 2016b), to the best of the present authors' knowledge, studies 
focusing on investigating withdrawal symptoms in relation to pornography use (apart from studies utilizing the self-report instruments in the present review) have rarely been reported in the literature, with the exception of recent qualitative research that found evidence of symptoms potentially resembling withdrawal in individuals who self-identify as being addicted to pornography (Ševčíková, Blinka \& Soukalová, 2018). In contrast, there has been neuroscientific evidence documenting that continued use of pornography over time might lead to effects resembling tolerance (e.g., Kühn and Gallinat, 2014). However, the difficulty of conceptualizing tolerance when applied to behavioral addictions in general (Billieux, Schimmenti, Khazaal, Maurage \& Heeren, 2015) could be another reason for the lack of inclusion by the instruments. Nonetheless, in their assessment, Böthe et al. (2017) did account for both quantitative aspects of tolerance ("I felt I had to watch more and more porn for satisfaction") and qualitative aspects of tolerance ("I gradually explored more 'extreme' porn, because the porn I watched was less satisfying"). Overall, more empirical research examining the nature of tolerance and withdrawal specifically with regards to pornography use is needed in order to better assess these components.

Craving has also been proposed to be a central component of addiction (Shaffer, 1999), and over the past few years there has been growing empirical support for the role of craving in the development and maintenance of addictive pornography use (Brand, Snagowski, Laier \& Maderwald, 2016; Laier, Pawlikowski, Pekal, Schulte \& Brand, 2013; Snagowski, Wegmann, Pekal, Laier \& Brand, 2015). However, only five scales assessed craving in some way. One scale (PCQ) is dedicated exclusively to the assessment of subjective craving for pornography and therefore has excellent research and clinical utility. Use despite harm was only assessed by two scales (PPUS and CYPAT) although this symptom has been described by addiction models as being central to the definition of addiction (Shaffer, 1999), as the disorder might be argued to be more about the individual's disregarding of the negative consequences rather than the presence of negative consequences itself. Scales assessing problematic pornography use could benefit from assessing craving and use despite harm, as both HD and CSBD criteria also refer to explicitly to sexual urges and continued use despite negative consequences or harm.

The more arguably 'peripheral' components of addiction (e.g., financial conflict, sleep conflict, household/hobby conflict, negative attitudes conflict and sex life conflict, and deception) were unsurprisingly less frequently assessed by the instruments, as they appear to act as secondary indicators of addictive use of pornography rather than primary indicators per se. However, it is interesting to note that of these 'peripheral' components, sex life conflict 
was the most frequently assessed, along with sleep conflict. Four out of the six instruments that assessed sleep conflict were based on adaptations of scales assessing internet addiction, of which sleep loss appears to be a significant manifestation, and does not appear to be a unique feature of problematic pornography use. However, what was unique to the assessment of problematic pornography use was conflict in terms of negative effects on sex life. In addition to questions concerning negative effects on sex life in general, specific negative effects explored were performance anxiety during sex (PCES), only having an orgasm when watching pornography (CPC), and only getting sexually aroused when watching pornography (CYPAT). Over the past couple of years, there have been clinical reports (Park et al., 2016; Porto, 2016) indicating that specific sexual dysfunctions such as erectile dysfunction and anorgasmia may result from chronic pornography use in some individuals, although empirical examination of this in the literature appears to be limited. Research to date has focused mainly on a possible association between pornography use and erectile dysfunction, although evidence for this association has generally been inconclusive (Berger et al., 2019; Grubbs \& Gola, 2019; Isenberg, 2015; Klein, Jurin, Briken \& Štulhofer, 2015; Landripet \& Štulhofer, 2015; Prause \& Pfaus, 2015). Thus, no conclusion can be drawn about the extent to which these dysfunctions reflect pornography dependence or otherwise, but remains a promising avenue for future research.

\section{Contextual factors potentially affecting assessment of addiction components}

Several contextual factors that may affect the assessment of addiction components in relation to pornography use need to be highlighted. First, the affordability of pornography use has the ability to affect the assessment of financial conflict. Pornography today can more often than not be accessed for free via the internet, thus the need to spend increasing amounts of money to purchase access to pornography may not manifest when compared to other problematic behaviors which may cost a significant amount of money. Novel measures such as the Pornography Purchase Task (PPT; Mulhauser, Short \& Weinstock, 2018) based on a behavioral economics paradigm, which ask participants using a hypothetical scenario how much money they would be willing to spend on pornography given different price points, may be able to account for this contextual characteristic of pornography use. The use of the hypothetical scenario would allow for the assessment continued engagement in the behavior despite significantly increasing financial costs - which would not be possible otherwise. Nonetheless, the specific extent to which responses on these kinds of measures would correspond to real-world scenarios where pornography use was expensive, is at present unknown but warrants further investigation. 
Second, the manner in which pornography consumption behavior takes place needs to be considered. In comparison with other problematic behaviors, such as gambling and gaming, pornography use, even when problematic, tends - in general - to take up less time. For instance, a non-clinical sample recently reported an average of 16-30 minutes per occasion viewing pornography (Böthe et al., 2017) while 95\% of a clinical sample of problematic pornography viewers viewed less than three hours of pornography a week (Reid et al., 2011b), which is at most an average of 25 minutes a day. Even if Cooper et al.'s (1999) cutoff of 11 hours per week as problematic were to be used, this would amount to an average of approximately 1.5 hours a day. When compared to duration spent on online gaming (average of 25 hours per week and up to 70 hours per week in extreme cases; Griffiths, Davies \& Chappell, 2004), the total amount of time spent viewing pornography is comparatively little. A possible explanation for the shorter duration of typical pornography use is that pornography use is more often than not accompanied by masturbation (Kraus \& Rosenberg, 2014; Reid et al., 2012b), and sexual stamina may become a factor, even during pornography binges (Wordecha et al., 2018). . Thus, if pornography use, even when it is problematic, does not take up a lot of time because it is limited by sexual stamina, then it may have less of a negative effect on areas of life such as sleep, and other leisure activities. However, this does not mean that other components of addiction may not be present (e.g., salience, impaired control, etc.) - but that the manner in which these manifest may not be reflected in time spent due to the sexual nature of the activity. At the same time, is important to note also that frequency of use or amount of use in and of itself is not a sufficient condition for addiction, because it is possible for frequency and/or amount of use to be high but for the behavior to not be problematic (Griffiths, 2010).

Third, the fact that pornography use (when compared to other potentially problematic behaviors) is sexual in nature may potentially influence the assessment of the craving component. There has been some debate within the field about whether high-frequency sexual behaviors represent a pathological manifestation of underlying hypersexuality/compulsive sexual behavior, or simply a (non-pathological) manifestation of high sexual desire, and about possible overlaps between the two constructs (e.g., Carvalho, Štulhofer, Vieira \& Jurin, 2015; Hilton, 2014; Kraus, Voon \& Potenza, 2016; Steele, Staley, Fong \& Prause, 2013; Winters, Christoff \& Gorzalka, 2010). It is plausible that the craving component in particular (when it comes to sexual behavior, including viewing pornography), might differ from craving for other problematic behaviors in that it may (in part) involve manifestations of general sexual desire (Kraus \& Rosenberg, 2014). Craving for other 
problematic behaviors (e.g., ingesting substances, gambling, and gaming), unlike sexual urges, arguably do not involve the attempted fulfillment of an innate biological drive. Therefore, it might be helpful to account for general sexual desire in some way when assessing craving for pornography. By extension, the presence and frequency of accompanying sexual behaviors (e.g., masturbation and/or sexual intercourse) may need to be accounted for as well in the assessment of problematic pornography use.

Fourth, as already has been acknowledged in the literature (Duffy et al., 2016; Humphreys, 2018), the morally-loaded and value-laden nature of pornography use and sexual behaviors in general are a significant contextual factor to consider in problematic pornography use assessment. Perceptions of pornography use as immoral, or as being out of line with one's values, have the potential to affect the assessment the following addiction components: intrapsychic conflict, interpersonal conflict, and deception. In terms of intrapsychic conflict, a whole body of work (see Grubbs, Perry, Wilt \& Reid, 2019a for a review) has suggested that for some individuals (especially religious individuals), using pornography while morally disapproving of pornography use may lead to emotional distress and shame resulting from moral incongruence. The ICD-11 diagnosis of CSBD (Kraus et al., 2018) acknowledges the potential confounding effects of moralistic judgments about sexual behavior and states that "distress that is entirely related to moral judgments and disapproval about sexual impulses, urges or behaviors is not sufficient to meet this requirement [for diagnosis]" (WHO, 2019, p. 1). Therefore, it is important in the assessment of problematic pornography use, for researchers and clinicians to differentiate between intrapsychic distress related to moral judgments of pornography use, as opposed to intrapsychic distress arising from a genuine addictive pattern, although the two are not mutually exclusive (Kraus \& Sweeney, 2019). It will be helpful for the field to develop validated measures of moral perceptions or values surrounding pornography use to help account for this factor. In addition, moral interpretations of pornography use also have the ability to influence the assessment of interpersonal conflict. As Vaillancourt-Morel and Bergeron (2019) have pointed out, it is important to consider the interpersonal contexts in which pornography use takes place, especially romantic relationships. For example, recent research showed that in a sample of 1755 mixed-sex couple pairs, only 14\% had identical levels of acceptance of pornography (Willoughby, Carroll, Busby \& Brown, 2016), suggesting that most couples may have some sort of discrepancy in their values surrounding pornography use in the context of a relationship. Also, because research has shown that men have more positive attitudes towards pornography than women (Johansson \& Hammarén, 2007), and frequent 
pornography consumption appears to be more common in men as opposed to women (e.g., Levin, Lillis, \& Hayes, 2012; Twohig, Crosby \& Cox, 2009) - there is a high likelihood of interpersonal conflict taking place within romantic relationships based on moral values, as opposed to the behavior itself necessarily being addictive or compulsive. Thus, it is important when assessing the interpersonal conflict component that potential moral disapproval of significant others be taken into account. By extension, this interpersonal context also has the ability to affect the assessment of the deception component, as the perception of social acceptability or unacceptability by the individual may impact the perceived need to keep the behavior secret. For example, where there may be incongruence in values towards pornography use of partners within a relationship, the pornography user may choose to hide or lie to their partner about their pornography use - not because they are addicted to the behavior, but to avoid conflict in the relationship. It is therefore important to ensure that deception due to covering up addictive behavior is differentiated from deception due to covering up behavior due to perceived social unacceptability of the behavior.

\section{Psychometric properties and sample characteristics}

In general, most of the instruments reviewed had robust psychometric properties demonstrating basic evidence of reliability and validity. However, six scales (Compulsive Use of Sexually Explicit Material, CCS, ISST, Habit Strength Scale, Deficient SelfRegulation Scale, and Negative Consequences Scale) did not undergo extensive psychometric evaluation. The ISST in particular had psychometric weaknesses, with two subscales having low levels of internal consistency, and with content validity issues. Thus, use of these scales needs further validation before its use can be recommended.

It is also important to note that most of the instruments in the present review were validated using very specific samples (e.g., adolescents, men who have sex with men, heterosexual men, men in general, etc.) which limits the generalizability of the findings across different samples. While female participants were sampled in a handful of studies, in general, participants across the studies were predominantly male. In addition, primarily nonclinical and Western samples were used in a large majority of the studies. Hence, more research is needed to validate these instruments across more diverse participant samples including clinical/treatment-seeking populations and across gender, age group, and sexual orientation.

\section{Recommendations for researchers and clinicians}

Overall, based on the findings of the present review, two instruments can be recommended for researchers and clinicians who wish to assess problematic pornography use 
based on their coverage of specific addiction components. The first instrument, the PPUS, although its coverage of addiction components was not the widest, assesses the most central components of addiction. Notably, the PPUS is the instrument that comes closest to assessing the same components assessed by HD criteria (8/10) and CSBD (7/9) - the missing components of which are craving and intrapsychic conflict, which the PPUS does not assess. The second instrument, the PPCS, is the only instrument that assessed all six of Griffiths' (2005) components, including explicitly assessing withdrawal and tolerance, which may be of particular research and/or clinical interest. The PPCS also provides a validated cutoff score to differentiate problematic from non-problematic pornography users which adds to its research and clinical utility. However, the assessment of the 'conflict' component on the PPCS is limited by its inclusion of the more 'peripheral' aspects of conflict (e.g., negative effects on sex life) and exclusion of the more central aspects of conflict (e.g., interpersonal conflict). However, wherever possible, the present authors recommend combining the use of different instruments included in this review depending on the type of information needed.

It is also important for researchers and clinicians to take into account variables that have the potential to confound problematic pornography use assessment, as has been discussed above. Caution needs to be exercised especially within treatment settings before reaching conclusions about clients being addicted to pornography not only because addiction cannot be assessed using self-report data alone, but because current understanding of the etiology of problematic pornography use is still in its infancy.

\section{Limitations}

The present review is not without its limitations. The review only covered self-report scales. Scales that assess problematic pornography use from a different person's perspective (e.g., partner's perspective in Perceived Partner's Pornography Use Scale; Stewart \& Szymanski, 2012) though useful, fell outside the scope of the present review. Additionally, the synthesis presented here included instruments that were not designed to strictly assess addiction symptoms (e.g., PCES and its derivatives), and as a result may have skewed observed trends of included addiction components. Finally, the present review only examined papers that described the initial use, development, or validation of an instrument - follow-up studies that used these instruments were not included and therefore limit any further information provided in the literature about psychometric properties of the instrument beyond the original validation sample.

\section{Conclusion}


Overall, while addiction has been the primary theoretical model by which problematic pornography use has been conceptualized in the literature, the lack of consensus among researchers about how to operationalize the condition poses a significant problem for the field. The diagnostic criteria for CSBD in the ICD-11, looks to be a promising resource in guiding future research endeavors in providing a unified framework and standardizing the assessment of problematic pornography use.

\section{References}

Abell, J. W., Steenbergh, T. A., \& Boivin, M. J. (2006). Cyberporn use in the context of religiosity. Journal of Psychology and Theology, 34(2), 165-171.

American Psychiatric Association. (2013). Diagnostic and statistical manual of mental disorders (5th ed.). Arlington, VA: American Psychiatric Publishing.

Bagby, R. M., Parker, J. D., \& Taylor, G. J. (1994). The twenty-item Toronto Alexithymia Scale-I. Item selection and cross-validation of the factor structure. Journal of Psychosomatic Research, 38(1), 23-32.

Bagby, R. M., Taylor, G. J., \& Parker, J. D. (1994). The twenty-item Toronto Alexithymia Scale-II. Convergent, discriminant, and concurrent validity. Journal of Psychosomatic Research, 38(1), 33-40.

Barth, R. J., \& Kinder, B. N. (1987). The mislabeling of sexual impulsivity. Journal of Sex and Marital Therapy, 13(1), 15-23.

Berger, J. H., Kehoe, J. E., Doan, A. P., Crain, D. S., Klam, W. P., Marshall, M. T., \& Christman, M. S. (2019). Survey of sexual function and pornography. Military Medicine. Advance online publication. https://doi.org/10.1093/milmed/usz079

Billieux, J., Schimmenti, A., Khazaal, Y., Maurage, P., \& Heeren, A. (2015). Are we overpathologizing everyday life? A tenable blueprint for behavioral addiction research. Journal of Behavioral Addictions, 4(3), 119-123.

Bőthe, B., Tóth-Király, I., Zsila, Á., Griffiths, M. D., Demetrovics, Z., \& Orosz, G. (2018). The development of the Problematic Pornography Consumption Scale (PPCS). Journal of Sex Research, 55(3), 395-406.

Brand, M., Antons, S., Wegmann, E., \& Potenza, M. N. (2018). Theoretical assumptions on pornography problems due to moral incongruence and mechanisms of addictive or compulsive use of pornography: Are the two "conditions" as theoretically distinct as suggested? Archives of Sexual Behavior. Advance online publication.

Brand, M., Snagowski, J., Laier, C., \& Maderwald, S. (2016). Ventral striatum activity when 
watching preferred pornographic pictures is correlated with symptoms of Internet pornography addiction. NeuroImage, 129, 224-232.

Brand, M., Laier, C., Pawlikowski, M., Schächtle, U., Schöler, T., \& Altstötter-Gleich, C. (2011). Watching pornographic pictures on the Internet: Role of sexual arousal ratings and psychological-psychiatric symptoms for using internet sex sites excessively. Cyberpsychology, Behavior, and Social Networking, 14(6), 371-377.

Brennan, K.A., Clark, C.L., \& Shaver, P.R. (1998). Self-report measurement of adult attachment: An integrative overview. In J.A. Simpson \& W.S. Rholes (Eds.), Attachment theory and close relationships (pp. 46-77). New York: Guilford.

Buzzell, T. (2005). Demographic characteristics of persons using pornography in three technological contexts. Sexuality \& Culture, 9(1), 28-48.

Cacioppo, M., Gori, A., Schimmenti, A., Baiocco, R., Laghi, F., \& Caretti, V. (2018). Development of a new screening tool for cyber pornography: Psychometric properties of the Cyber Pornography Addiction Test (CYPAT). Clinical Neuropsychiatry: Journal of Treatment Evaluation, 15(1), 60-65.

Carnes, P. J. (1983). Out of the shadows: Understanding sexual addiction. Minneapolis, MN: CompCare.

Carnes, P. J. (1989). Contrary to love: Helping the sexual addict. Minneapolis, MN: CompCare Publishing.

Carnes, P. J., Green, B. A., Merlo, L. J., Polles, A., Carnes, S., \& Gold, M. S. (2012). PATHOS: A brief screening application for assessing sexual addiction. Journal of Addiction Medicine, 6(1), 29-34.

Carvalho, J., Štulhofer, A., Vieira, A. L., \& Jurin, T. (2015). Hypersexuality and high sexual desire: Exploring the structure of problematic sexuality. Journal of Sexual Medicine, 12(6), 1356-1367.

Cicchetti, D. V. (1994). Guidelines, criteria, and rules of thumb for evaluating normed and standardized assessment instruments in psychology. Psychological Assessment, 6(4), 284-290.

Cohen, S., Kamarck, T., \& Mermelstein, R. (1983). A global measure of perceived stress. Journal of Health and Social Behavior, 24(4), 385-396.

Coleman, E. (1991). Compulsive sexual behavior. Journal of Psychology and Human Sexuality, 4(2), 37-52.

Coleman, E., Miner, M., Ohlerking, F., \& Raymond, N. (2001). Compulsive Sexual Behavior 
Inventory: A preliminary study of reliability and validity. Journal of Sex \& Marital Therapy, 27(4), 325-332.

Cooper, A. (1998). Sexuality and the Internet: Surfing into the new millennium.

CyberPsychology \& Behavior, 1(2), 187-193.

Cooper, A., Scherer, C. R., Boies, S. C., \& Gordon, B. L. (1999). Sexuality on the Internet: From sexual exploration to pathological expression. Professional Psychology: Research and Practice, 30(2), 154-164.

Costa, P. T., \& McCrae, R. R. (1992). Revised NEO Personality Inventory (NEO-PI-R) and NEO Five-Factor Inventory Professional Manual. Odessa, FL: Psychological Assessment Resources.

Cunningham-Williams, R. M., Gattis, M. N., Dore, P. M., Shi, P., \& Spitznagel Jr, E. L. (2009). Towards DSM-V: considering other withdrawal-like symptoms of pathological gambling disorder. International Journal of Methods in Psychiatric Research, 18(1), 13-22.

Cuzen, N. L., \& Stein, D. J. (2014). Behavioral addiction: The nexus of impulsivity and compulsivity. In Rosenberg, K. P., \& Feder, L. C. (Eds.), Behavioral Addictions: Criteria, Evidence and Treatment (pp. 19-34). Oxford: Elsevier.

Delmonico, D. L., \& Miller, J. A. (2003). The Internet Sex Screening Test: A comparison of sexual compulsives versus non-sexual compulsives. Sexual and Relationship Therapy, $18(3), 261-276$.

Doornwaard, S. M., van den Eijnden, R. J. J. M., Baams, L., Vanwesenbeeck, I., \& ter Bogt, T. F. M. (2016). Lower psychological well-being and excessive sexual interest predict symptoms of compulsive use of sexually explicit internet material among adolescent boys. Journal of Youth and Adolescence, 45(1), 73-84.

Downing, M. J. J., Antebi, N., Schrimshaw, E. W., Downing Jr., M. J., Antebi, N., \& Schrimshaw, E. W. (2014). Compulsive use of Internet-based sexually explicit media: Adaptation and validation of the Compulsive Internet Use Scale (CIUS). Addictive Behaviors, 39(6), 1126-1130.

Duffy, A., Dawson, D. L., \& das Nair, R. (2016). Pornography addiction in adults: A systematic review of definitions and reported impact. Journal of Sexual Medicine, 13(5), 760-777.

Eleuteri, S., Tripodi, F., Petruccelli, I., Rossi, R., \& Simonelli, C. (2014). Questionnaires and scales for the evaluation of the online sexual activities: A review of 20 years of research. Cyberpsychology: Journal of Psychosocial Research on Cyberspace, 8(1). 
Fernandez, D. P., Tee, E. Y. J., \& Fernandez, E. F. (2017). Do Cyber Pornography Use Inventory-9 scores reflect actual compulsivity in internet pornography use? Exploring the role of abstinence effort. Sexual Addiction and Compulsivity, 24(3), 156-179.

Franke, G. H. (2002). SCL-90-R-Die Symptom-Checkliste von L. R. Derogatis. Göttingen, Germany: Beltz Test.

Gola, M., Wordecha, M., Sescousse, G., Lew-Starowicz, M., Kossowski, B., Wypych, M., ... Marchewka, A. (2017). Can pornography be addictive? An fMRI study of men seeking treatment for problematic pornography use. Neuropsychopharmacology, 42(10), 2021-2031.

Goodman, A. (1992). Sexual addiction: Designation and treatment. Journal of Sex and Marital Therapy, 18(4), 303-314.

Griffiths, M. D. (1999). Internet addiction: Fact or fiction? The Psychologist: Bulletin of the British Psychological Society, 12, 246-250.

Griffiths, M. D. (2005). A ‘components' model of addiction within a biopsychosocial framework. Journal of Substance Use, 10(4), 191-197.

Griffiths, M. D. (2010). The role of context in online gaming excess and addiction: Some case study evidence. International Journal of Mental Health and Addiction, 8(1), $119-125$.

Griffiths, M. D., Davies, M. N. O., \& Chappell, D. (2004). Demographic factors and playing variables in online computer gaming. CyberPsychology \& Behavior, 7(4), 479-487.

Grubbs, J. B., \& Gola, M. (2019). Is pornography use related to erectile functioning? Results from cross-sectional and latent growth curve analyses. Journal of Sexual Medicine, 16(1), 111-125.

Grubbs, J. B., Perry, S. L., Wilt, J. A., \& Reid, R. C. (2019a). Pornography problems due to moral incongruence: An integrative model with a systematic review and meta -analysis. Archives of Sexual Behavior, 48, 397-415

Grubbs, J. B., Perry, S. L., Wilt, J. A., \& Reid, R. C. (2019b). Response to commentaries. Archives of Sexual Behavior, 48(2), 461-468.

Grubbs, J. B., Sessoms, J., Wheeler, D. M., \& Volk, F. (2010). The cyber-pornography use inventory: The development of a new assessment instrument. Sexual Addiction and Compulsivity, 17(2), 106-126.

Grubbs, J. B., Volk, F., Exline, J. J., \& Pargament, K. I. (2015). Internet pornography use: Perceived addiction, psychological distress, and the validation of a brief measure. Journal of Sex and Marital Therapy, 41(1), 83-106. 
Hald, G. M., Kuyper, L., Adam, P. C. G., \& de Wit, J. B. F. (2013). Does viewing explain doing? Assessing the association between sexually explicit materials use and sexual behaviors in a large sample of Dutch adolescents and young adults. Journal of Sexual Medicine, 10(12), 2986-2995.

Hald, G. M., \& Malamuth, N. M. (2008). Self-perceived effects of pornography consumption. Archives of Sexual Behavior, 37(4), 614-625.

Hald, G. M., \& Mulya, T. W. (2013). Pornography consumption and non-marital sexual behavior in a sample of young Indonesian university students. Culture, Health \& Sexuality, 15(8), 981-996.

Hald, G. M., Smolenski, D., \& Rosser, B. R. S. (2013). Perceived effects of sexually explicit media among men who have sex with men and psychometric properties of the Pornography Consumption Effects Scale (PCES). Journal of Sexual Medicine, 10(3), $757-767$.

Hartmann, U. H. (2013). Re: Report of findings in a DSM-5 field trial for hypersexual disorder. European Urology, 64(4), 685-686.

Hilton, D. L., Jr. (2013). Pornography addiction - A supranormal stimulus considered in the context of neuroplasticity. Socioaffective Neuroscience \& Psychology, 3(1), 20767.

Hilton Jr, D. L. (2014). 'High desire', or 'merely' an addiction? A response to Steele et al. Socioaffective Neuroscience \& Psychology, 4(1), 23833.

Hook, J. N., Hook, J. P., Davis, D. E., Worthington, E. L., \& Penberthy, J. K. (2010). Measuring sexual addiction and compulsivity: A critical review of instruments. Journal of Sex \& Marital Therapy, 36(3), 227-260.

Hoyle, R. H., Stephenson, M. T., Palmgreen, P., Lorch, E. P., \& Donohew, R. L. (2002). Reliability and validity of a brief measure of sensation seeking. Personality and Individual Differences, 32(3), 401-414.

Humphreys, K. (2018). Of moral judgments and sexual addictions. Addiction, 113(3), 387388.

Isenberg, R. A. (2015). Viewing sexual stimuli associated with greater sexual responsiveness, not erectile dysfunction: A comment. Sexual Medicine, 3(3), 219-221.

Johansson, T., \& Hammarén, N. (2007). Hegemonic masculinity and pornography: Young people's attitudes toward and relations to pornography. Journal of Men's Studies, $15(1), 57-70$.

Kandel, D. B., \& Davies, M. (1982). Epidemiology of depressive mood in adolescents: An empirical study. Archives of General Psychiatry, 39(10), 1205-1212. 
Kafka, M. P. (2010). Hypersexual disorder: A proposed diagnosis for DSM-V. Archives of Sexual Behavior, 39(2), 377-400.

Kaptsis, D., King, D. L., Delfabbro, P. H., \& Gradisar, M. (2016a). Withdrawal symptoms in Internet gaming disorder: A systematic review. Clinical Psychology Review, 43, 5866.

Kaptsis, D., King, D. L., Delfabbro, P. H., \& Gradisar, M. (2016b). Trajectories of abstinence-induced Internet gaming withdrawal symptoms: A prospective pilot study. Addictive Behaviors Reports, 4, 24-30.

Kalichman, S. C., \& Rompa, D. (1995). Sexual Sensation Seeking and Sexual Compulsivity Scales: Reliability, validity, and predicting HIV risk behavior. Journal of Personality Assessment, 65(3), 586-601.

King, D. L., Haagsma, M. C., Delfabbro, P. H., Gradisar, M., \& Griffiths, M. D. (2013). Toward a consensus definition of pathological video-gaming: A systematic review of psychometric assessment tools. Clinical Psychology Review, 33(3), 331-342.

Kingston, D. A., \& Firestone, P. (2008). Problematic hypersexuality: A review of conceptualization and diagnosis. Sexual Addiction and Compulsivity, 15(4), 284-310.

Klein, V., Jurin, T., Briken, P., \& Štulhofer, A. (2015). Erectile dysfunction, boredom, and hypersexuality among coupled men from two European countries. Journal of Sexual Medicine, 12(11), 2160-2167.

Kor, A., Zilcha-Mano, S., Fogel, Y. A., Mikulincer, M., Reid, R. C., \& Potenza, M. N. (2014). Psychometric development of the Problematic Pornography Use Scale. Addictive Behaviors, 39(5), 861-868.

Kraus, S. W., Krueger, R. B., Briken, P., First, M. B., Stein, D. J., Kaplan, M. S., ... Reed, G. M. (2018). Compulsive sexual behavior disorder in the ICD-11. World Psychiatry, 17(1), 109-110.

Kraus, S. W., Martino, S., \& Potenza, M. N. (2016). Clinical characteristics of men interested in seeking treatment for use of pornography. Journal of Behavioral Addictions, 5(2), 169-178.

Kraus, S., \& Rosenberg, H. (2014). The pornography craving questionnaire: Psychometric properties. Archives of Sexual Behavior, 43(3), 451-462.

Kraus, S. W., \& Sweeney, P. J. (2019). Hitting the target: Considerations for differential diagnosis when treating individuals for problematic use of pornography. Archives of Sexual Behavior, 48(2), 431-435

Kraus, S. W., Voon, V., \& Potenza, M. N. (2016). Should compulsive sexual behavior be 
considered an addiction? Addiction, 111(12), 2097-2106.

Kühn, S., \& Gallinat, J. (2014). Brain structure and functional connectivity associated with pornography consumption the brain on porn. JAMA Psychiatry, 71(7), 827-834.

Laier, C., Pawlikowski, M., Pekal, J., Schulte, F. P., \& Brand, M. (2013). Cybersex addiction: Experienced sexual arousal when watching pornography and not real-life sexual contacts makes the difference. Journal of Behavioral Addictions, 2(2), 100-107.

Landripet, I., \& Štulhofer, A. (2015). Is pornography use associated with sexual difficulties and dysfunctions among younger heterosexual men? The Journal of Sexual Medicine, 12(5), 1136-1139.

LaRose, R., Kim, J. H., \& Peng, W. (2010). Social networking: Addictive, compulsive, problematic, or just another media habit. In Z. Papacharissi (Ed.), A networked self: Identity, community, and culture on social network sites (pp. 59-81). London, UK: Routledge.

LaRose, R., Lin, C., \& Eastin, M. (2003). Unregulated Internet usage: Addiction, habit, or deficient self-regulation. Media Psychology, 5(3), 225-253.

Levin, M. E., Lillis, J., \& Hayes, S. C. (2012). When is online pornography viewing problematic among college males? Examining the moderating role of experiential avoidance. Sexual Addiction \& Compulsivity, 19(3), 168-180.

Ley, D., Prause, N., \& Finn, P. (2014). The emperor has no clothes: A review of the 'pornography addiction' model. Current Sexual Health Reports, 6(2), 94-105.

Love, T., Laier, C., Brand, M., Hatch, L., \& Hajela, R. (2015). Neuroscience of internet pornography addiction: A review and update. Behavioral Sciences, 5(3), 388433.

Maddux, J. F., \& Desmond, D. P. (2000). Addiction or dependence? Addiction, 95(5), 661 -665 .

McKee, A. (2007). The positive and negative effects of pornography as attributed by consumers. Australian Journal of Communication, 34(1), 87-104.

Meerkerk, G.-J., Van Den Eijnden, R. J. J. M., Vermulst, A. A., \& Garretsen, H. F. L. (2009). The Compulsive Internet Use Scale (CIUS): Some psychometric properties. CyberPsychology \& Behavior, 12(1), 1-6.

Miller, D. J., Kidd, G., \& Hald, G. M. (2019). Measuring self-perceived effects of pornography: A short-form version of the Pornography Consumption Effects Scale. Archives of Sexual Behavior, 48(3), 753-761.

Montgomery-Graham, S. (2017). Conceptualization and assessment of Hypersexual Disorder: A systematic review of the literature. Sexual Medicine Reviews, 5(2), 146-162. 
Mulhauser, K., Miller Short, E., \& Weinstock, J. (2018). Development and psychometric evaluation of the Pornography Purchase Task. Addictive Behaviors, 84, 207-214.

Nijenhuis, E. R. S., Van der Hart, \& Vanderlinden, J. (1999). The Traumatic Experiences Checklist (TEC). In E. R. S. Nijenhuis (Ed.), Somatoform dissociation: Phenomena, measurement, and theoretical issues (pp. 188-193). Assen, the Netherlands: Van Gorcum

Noor, S. W., Rosser, B. R. S., \& Erickson, D. J. (2014). A brief scale to measure problematic sexually explicit media consumption: Psychometric properties of the Compulsive Pornography Consumption (CPC) scale among men who have sex with men. Sexual Addiction \& Compulsivity, 21(3), 240-261.

O'Neil, J. M., Helms, B. J., Gable, R. K., David, L., \& Wrightsman, L. S. (1986). Gender -Role Conflict Scale: College men's fear of femininity. Sex Roles, 14(5-6), 335-350.

Olson, D. (2011). FACES IV and the circumplex model: Validation study. Journal of Marital and Family Therapy, 37(1), 64-80.

Park, B. Y., Wilson, G., Berger, J., Christman, M., Reina, B., Bishop, F., Doan, A. P. (2016). Is internet pornography causing sexual dysfunctions? A review with clinical reports. Behavioral Sciences, 6(3), 17.

Parsons, J. T., Rendina, H. J., Ventuneac, A., Cook, K. F., Grov, C., \& Mustanski, B. (2013). A psychometric investigation of the Hypersexual Disorder Screening Inventory among highly sexually active gay and bisexual men: An item response theory analysis. Journal of Sexual Medicine, 10(12), 3088-3101.

Pornhub.com (2018, January 9). 2017 year in review. Retrieved March 6, 2018, from: https://www.pornhub.com/insights/2017-year-in-review

Porto, R. (2016). Habitudes masturbatoires et dysfonctions sexuelles masculines. Sexologies, 25(4), 160-165.

Prause, N., \& Pfaus, J. (2015). Viewing sexual stimuli associated with greater sexual responsiveness, not erectile dysfunction. Sexual Medicine, 3(2), 90-98.

Reed, G. M., First, M. B., Kogan, C. S., Hyman, S. E., Gureje, O., Gaebel, W., ... \& Claudino, A. (2019). Innovations and changes in the ICD-11 classification of mental, behavioural and neurodevelopmental disorders. World Psychiatry, 18(1), 3-19.

Reid, R. C., Carpenter, B. N., Hook, J. N., Garos, S., Manning, J. C., Gilliland, R., .. Fong, T. (2012b). Report of findings in a DSM-5 field trial for Hypersexual Disorder. Journal of Sexual Medicine, 9(11), 2868-2877.

Reid, R. C., Garos, S., \& Carpenter, B. N. (2011a). Reliability, validity, and psychometric 
development of the hypersexual behavior inventory in an outpatient sample of men. Sexual Addiction and Compulsivity, 18(1), 30-51.

Reid, R. C., Garos, S., \& Fong, T. (2012a). Psychometric development of the Hypersexual Behavior Consequences Scale. Journal of Behavioral Addictions, 1(3), 115-122.

Reid, R. C., \& Kafka, M. P. (2014). Controversies about Hypersexual Disorder and the DSM-5. Current Sexual Health Reports, 6(4), 259-264.

Reid, R. C., Li, D. S., Gilliland, R., Stein, J. A., \& Fong, T. (2011b). Reliability, validity, and psychometric development of the Pornography Consumption Inventory in a sample of hypersexual men. Journal of Sex and Marital Therapy, 37(5), 359-385.

Reynolds, W. M. (1982). Development of reliable and valid short forms of the Marlowe -Crowne Social Desirability Scale. Journal of Clinical Psychology, 38(1), 119-125.

Rosenberg, H., \& Kraus, S. (2014). The relationship of "passionate attachment" for pornography with sexual compulsivity, frequency of use, and craving for pornography. Addictive Behaviors, 39(5), 1012-1017.

Rosenberg, M. (1965). Society and the adolescent self-image. Princeton, NJ: Princeton University Press.

Schneider, J. P. (1994). Sex addiction: Controversy within mainstream addiction medicine, diagnosis based on the DSM-III-R, and physician case histories. Sexual Addiction and Compulsivity, 1(1), 19-44.

Ševčíková, A., Blinka, L., \& Soukalová, V. (2018). Excessive internet use for sexual purposes among members of Sexaholics Anonymous and Sex Addicts Anonymous. Sexual Addiction \& Compulsivity, 25(1), 65-79.

Sirianni, J. M., \& Vishwanath, A. (2016). Problematic online pornography use: A media attendance perspective. Journal of Sex Research, 53(1), 21-34.

Shaffer, H. J. (1999). Strange bedfellows: A critical view of pathological gambling and addiction. Addiction, 94(10), 1445-1448.

Smolenski, D. J., Diamond, P. M., Ross, M. W., \& Rosser, B. R. S. (2010). Revision, criterion validity, and multigroup assessment of the reactions to homosexuality scale. Journal of Personality Assessment, 92(6), 568-576.

Snagowski, J., Wegmann, E., Pekal, J., Laier, C., \& Brand, M. (2015). Implicit associations in cybersex addiction: Adaption of an Implicit Association Test with pornographic pictures. Addictive Behaviors, 49, 7-12.

Snell, W. E., Fisher, T. D., \& Walters, A. S. (1993). The Multidimensional Sexuality 
Questionnaire: An objective self-report measure of psychological tendencies associated with human sexuality. Annals of Sex Research, 6(1), 27-55.

Snell, W. E., \& Papini, D. R. (1989). The Sexuality Scale: An instrument to measure sexual -esteem, sexual-depression, and sexual-preoccupation. Journal of Sex Research, 26(2), 256-263.

Spanier, G.B. (1976). Measuring dyadic adjustment: new scales for assessing the quality of marriage and similar dyads. Journal of Marriage and the Family, 38(1), 15-38.

Spielberger, C. D., Gorsuch, R. L., Lushene, R., Vagg, P. R., \& Jacobs, G. A. (1983). Manual for the State-Trait Anxiety Inventory. Palo Alto, CA: Consulting Psychologists Press.

Starcevic, V. (2016). Tolerance and withdrawal symptoms may not be helpful to enhance understanding of behavioral addictions. Addiction, 111(7), 1307-1308.

Steele, V. R., Staley, C., Fong, T., \& Prause, N. (2013). Sexual desire, not hypersexuality, is related to neurophysiological responses elicited by sexual images. Socioaffective Neuroscience \& Psychology, 3(1), 20770.

Stewart, D. N., \& Szymanski, D. M. (2012). Young adult women's reports of their male romantic partner's pornography use as a correlate of their self-esteem, relationship quality, and sexual satisfaction. Sex Roles, 67(5-6), 257-271.

Stöber, J. (2001). The Social Desirability Scale-17 (SDS-17): Convergent validity, discriminant validity, and relationship with age. European Journal of Psychological Assessment, 17(3), 222-232.

Strahan, R., \& Gerbasi, K. C. (1972). Short, homogeneous versions of the Marlowe-Crowne social desirability scale. Journal of Clinical Psychology, 28(2), 191-193.

Szymanski, D. M., \& Stewart-Richardson, D. N. (2014). Psychological, relational, and sexual correlates of pornography use on young adult heterosexual men in romantic relationships. Journal of Men's Studies, 22(1), 64-82.

Thompson, E. R. (2007). Development and validation of an internationally reliable short -form of the positive and negative affect schedule (PANAS). Journal of CrossCultural Psychology, 38(2), 227-242.

Twohig, M. P., Crosby, J. M., \& Cox, J. M. (2009). Viewing Internet pornography: For whom is it problematic, how, and why? Sexual Addiction \& Compulsivity, 16(4), 253266.

Vaillancourt-Morel, M.-P., \& Bergeron, S. (2019). Self-perceived problematic pornography use: Beyond individual differences and religiosity. Archives of Sexual Behavior, 48, 437-441. 
Vallerand, R. J., Mageau, G. A., Ratelle, C., Léonard, M., Blanchard, C., Koestner, R., ... Marsolais, J. (2003). Les Passions de 1'Âme: On Obsessive and Harmonious Passion. Journal of Personality and Social Psychology, 85(4), 756-767.

van Baardewijk, Y., Andershed, H., Stegge, H., Nilsson, K. W., Scholte, E., \& Vermeiren, R. (2010). Development and tests of short versions of the Youth Psychopathic Traits Inventory and the Youth Psychopathic Traits Inventory-Child Version. European Journal of Psychological Assessment, 26(2), 122-128.

van Rooij, A. J., Kuss, D. J., Griffiths, M. D., Shorter, G. W., Schoenmakers, T. M., \& van de Mheen, D. (2014). The (co-)occurrence of problematic video gaming, substance use, and psychosocial problems in adolescents. Journal of Behavioral Addictions, 3(3), $157-165$.

Voros, F. (2009). The invention of addiction to pornography. Sexologies, 18(4), 243-246.

Wéry, A., \& Billieux, J. (2017). Problematic cybersex: Conceptualization, assessment, and treatment. Addictive Behaviors, 64, 238-246.

Wéry, A., Burnay, J., Karila, L., \& Billieux, J. (2016). The short French Internet Addiction Test adapted to online sexual activities: Validation and links with online sexual preferences and addiction symptoms. Journal of Sex Research, 53(6), 701-710.

Wichstrøm, L. (1995). Harter's Self-Perception Profile for Adolescents: Reliability, validity, and evaluation of the question format. Journal of Personality Assessment, 65(1), 100116.

Widyanto, L., \& McMurran, M. (2004). The psychometric properties of the internet addiction test. CyberPsychology \& Behavior, 7(4), 443-450.

Willoughby, B. J., Carroll, J. S., Busby, D. M., \& Brown, C. C. (2016). Differences in pornography use among couples: Associations with satisfaction, stability, and relationship processes. Archives of Sexual Behavior, 45(1), 145-158.

Wilson, G. (2014). Your brain on porn: Internet pornography and the emerging science of addiction. Richmond, VA: Commonwealth Publishing.

Winters, K. C., Stinchfield, R. D., \& Fulkerson, J. (1993). Toward the development of an adolescent gambling problem severity scale. Journal of Gambling Studies, 9(1), 6384.

Womack, S. D., Hook, J. N., Ramos, M., Davis, D. E., \& Penberthy, J. K. (2013). Measuring hypersexual behavior. Sexual Addiction and Compulsivity, 20(1-2), 65-78.

Wordecha, M., Wilk, M., Kowalewska, E., Skorko, M., Łapiński, A., \& Gola, M. (2018). 
"Pornographic binges" as a key characteristic of males seeking treatment for compulsive sexual behaviors: Qualitative and quantitative 10-week-long diary assessment. Journal of Behavioral Addictions, 7(2), 433-444.

World Health Organization (2019). ICD-11: International classification of diseases $11^{\text {th }}$ edition Retrieved May 24, 2019 from https://icd.who.int/en/

Winters, J., Christoff, K., \& Gorzalka, B. B. (2010). Dysregulated sexuality and high sexual desire: Distinct constructs? Archives of Sexual Behavior, 39(5), 1029-1043.

Wright, P. J. (2013). U.S. males and pornography, 1973-2010: Consumption, predictors, correlates. Journal of Sex Research, 50(1), 60-71.

Young, K. S. (1998). Caught in the Net: How to recognize the signs of Internet addiction - And a winning strategy for recovery. New York, NY: Wiley 